\title{
The NAD+-Dependent Histone Deacetylase Sirtuin-2 is Upregulated during Myogenesis and Promotes the Differentiation of C2C12 Myoblasts
}

\author{
David A. Stanton
}

Follow this and additional works at: https://researchrepository.wvu.edu/etd

\section{Recommended Citation}

Stanton, David A., "The NAD+-Dependent Histone Deacetylase Sirtuin-2 is Upregulated during Myogenesis and Promotes the Differentiation of C2C12 Myoblasts" (2017). Graduate Theses, Dissertations, and Problem Reports. 6715.

https://researchrepository.wvu.edu/etd/6715

This Thesis is protected by copyright and/or related rights. It has been brought to you by the The Research Repository @WVU with permission from the rights-holder(s). You are free to use this Thesis in any way that is permitted by the copyright and related rights legislation that applies to your use. For other uses you must obtain permission from the rights-holder(s) directly, unless additional rights are indicated by a Creative Commons license in the record and/ or on the work itself. This Thesis has been accepted for inclusion in WVU Graduate Theses, Dissertations, and Problem Reports collection by an authorized administrator of The Research Repository @ WVU. For more information, please contact researchrepository@mail.wvu.edu. 


\title{
The NAD ${ }^{+}$-Dependent Histone Deacetylase Sirtuin- 2 is Upregulated during Myogenesis and Promotes the Differentiation of C2C12 Myoblasts
}

\author{
David A. Stanton, B.S.
}

Thesis submitted to the School of Medicine, Division of Exercise Physiology at West Virginia University in partial fulfillment of the requirements for the degree of Master of Science in Exercise Physiology

Stephen E. Alway, Ph.D., Chair

Randall W. Bryner, Ed.D

Emidio E. Pistilli, Ph.D.

Junaith S. Mohamed, Ph.D.

Division of Exercise Physiology

Morgantown, WV

2017

Keywords: Satellite cells, Myogenesis, Sirt2, C2C12 Myoblasts, pRB, E2F1 


\title{
Abstract \\ The NAD ${ }^{+}$-Dependent Histone Deacetylase Sirtuin-2 is Upregulated during Myogenesis and Promotes the Differentiation of C2C12 Myoblasts
}

\author{
David A. Stanton
}

The postnatal growth and regenerative capacity of skeletal muscle rely on the successful activation and differentiation of muscle stem cells known as satellite cells. Although the NAD ${ }^{+}-$ dependent protein deacetylase sirtuin-2 (Sirt2) has been suggested to have a role as a redox sensor during myogenesis, and in the regulation of metabolism, microtubule dynamics, and exit from the cell cycle exit, it is not known if Sirt2 has a regulatory role in muscle stem cell differentiation. This study aimed to elucidate the regulation of Sirt2 during the myogenic program of muscle satellite cells. The $\mathrm{C} 2 \mathrm{C} 12$ mouse myoblast cell line was used to examine the regulatory mechanisms of Sirt2 during the differentiation process. Several cell lines were used during experimentation including wild type (-) cells, cells supplemented with the Sirt2 inhibitor BML-266, and cells which were transfected with CRISPR/Cas9 plasmids to generate both Sirt2 knockdown (SKO) and control plasmid (CC) lines. Assays were conducted at time points from 0h-96h following the induction of differentiation to assess Sirt2 regulation and downstream interactions. Sirt $2 \mathrm{mRNA}$ and protein expression were elevated during the early stages of differentiation at the $12 \mathrm{~h}$ time point in the (-) cells. A significant decrease in the myotube fusion index of both BML-266 and SKO cell lines was observed, indicating Sirt2 deacetylase activity is important in regulating the normal formation of myotubes. Immunoprecipitation experimentation was performed to evaluate Sirt2 protein interactions and possible downstream signaling targets. Sirt2 was observed to interact with the cell cycle inhibitor retinoblastoma (pRB), as well as p21 and E2F1 a regulator of cellular proliferation. The acetylation status of E2F1 was significantly decreased at the $12 \mathrm{~h}$ time point coinciding with the increased Sirt2 protein expression observed at the same point. These results indicate that Sirt2 mediates its control of myogenesis through interaction and complex formation with proteins associated with the cell cycle, and that this interaction mediates exit from the cell cycle and the induction of terminal differentiation leading to the formation of myofibers. Elucidation of Sirt2 as a regulator of differentiation during myogenesis thus presents a possible therapeutic target in conditions such as aging, as expression of the sirtuins and their cofactor $\mathrm{NAD}^{+}$both decrease in aged phenotypes. 


\section{Table of Contents}

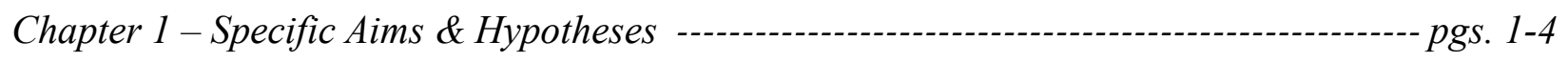

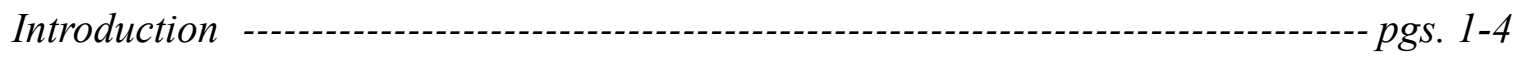

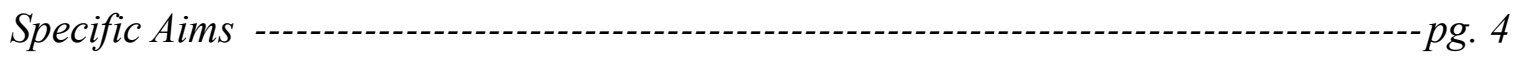

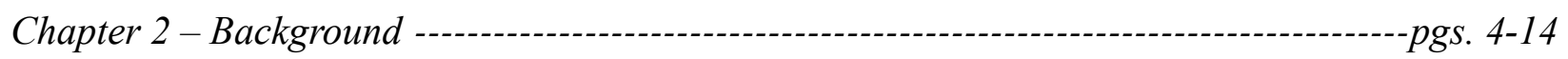

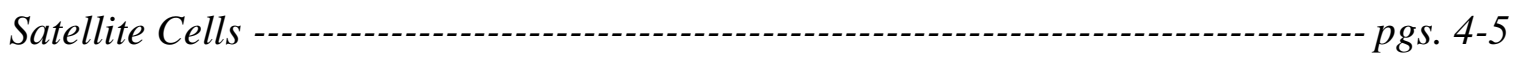

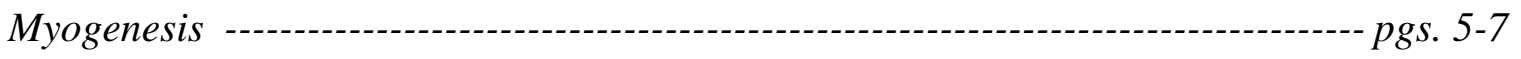

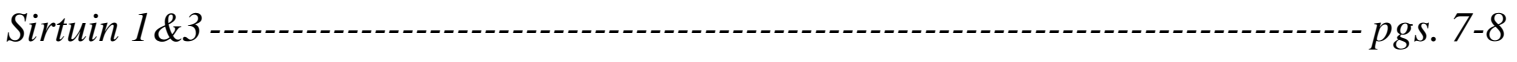

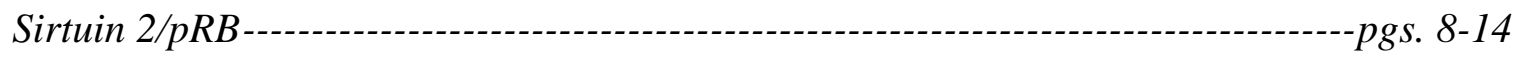

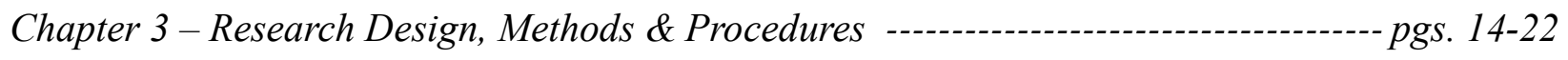

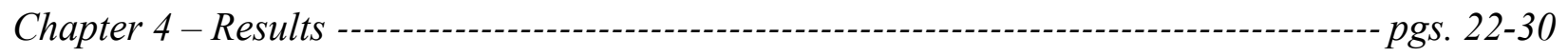

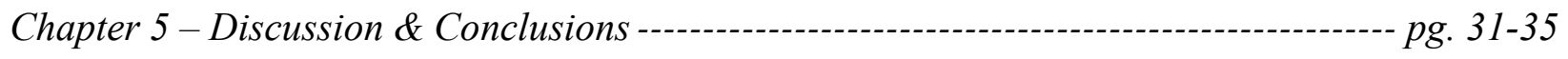

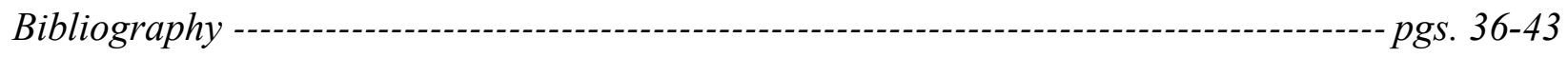

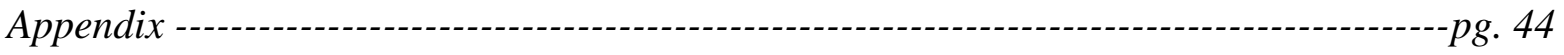




\section{Chapter 1-Specific Aims \& Hypotheses}

\section{Introduction}

The postnatal growth and regenerative capacity of skeletal muscle relies on the successful activation of quiescent muscle stem cells known as satellite cells (SC). The satellite cell lies between the sarcolemma and the basal lamina of a muscle fiber and was first identified by Alexander Mauro in 1961 [1]. The process of activating these quiescent satellite cells, and the subsequent muscle formation for the functions of growth and repair, is known as myogenesis [2]. Once activated, proliferating satellite cells may either donate their nuclei to existing muscle fibers promoting growth, or they can differentiate and fuse to generate new muscle fibers (myotubes) which can replace injured fibers and restore normal muscle function. The formation of new fibers during myogenesis is termed hyperplasia, and stretch-overload experimentation performed by Alway et al. [3] demonstrated the remarkable capacity for satellite cells to proliferate and form new muscle fibers via this mechanism.

Investigating the molecular and genetic mechanisms that regulate myogenesis is vital, as impaired myogenesis impacts muscular regeneration in various conditions such as aging, muscular dystrophy, and muscle wasting (cachexia) associated with many forms of cancer [4-7]. The occurrence of defects at any stage of myogenesis severely affects the formation of new muscle fibers; however, the mechanisms that inhibit the function of satellite cells in various pathophysiological conditions are characterized insufficiently [8].

Potential candidate genes that may play a role in the regulation of myogenesis include members of the Sirtuin family [9-11]. For example, muscle-specific inactivation of the deacetylase domain of Sirtuin1 (Sirt1; one of the seven members of the Sirtuin family) reduces myofiber size, 
impairs muscular regeneration, and suppresses muscle developmental gene expression [10]. , Sirt3 is also involved in the regulation of myoblast differentiation through mitochondrial pathways [11].

Little is known about the role of Sirt2 in myogenesis. It is known that Sirt2 shares similarities to Sirt1, including the enzymatic regulation of essential cellular processes such as metabolism, cellular health, and genomic stability [12-17]. In non-muscle cells, Sirt2 acts as a universal histone deacetylase like Sirt1 [18]. Beyond its similarities to Sirt1, Sirt2 plays a role in the proliferation of myoblasts [19], and the differentiation of several cell populations, including oligodendroglial cells [20], and adipocytes [21]. Additionally, Sirt2 has been shown to inhibit the E3 ubiquitin ligases to suppress tumor cell growth [22], yet downregulation of Sirt2 is protective against ischemia-reperfusion injury in heart cells [23]. Reduced Sirt2 function directly diminishes deacetylation of PGC-1 $\alpha$ and expression of $\beta$-oxidation and mitochondrial genes in adipocytes [24].

Sirt2 has several characterized roles in cell cycle regulation, including cell cycle progression, genome stability, and mitotic exit from the cell cycle [25-27]. The retinoblastoma family of proteins, including RB/p105 (pRB), represent attractive targets in cell cycle progression. The pRB protein is responsible for a significant checkpoint in the G1 phase of the cell cycle through its interaction with the E2F family of transcription factors [28] where it blocks S-phase entry, thereby promoting terminal differentiation by inducing both cell cycle exit and tissue specific gene expression [29]. The activity of $\mathrm{pRB}$ is regulated by both phosphorylation and acetylation events, with the active form of pRB being hypo-phosphorylated and acetylated on multiple residues. The hyper-phosphorylation of $\mathrm{pRB}$ by cyclin dependent kinases and the deacetylation of pRB by histone deacetylases inhibit its activity [29,30], and Wong et al. have previously characterized Sirt1 as a potent deacetylase for pRB [31]. Therefore, it is necessary to 
investigate the potential interaction between Sirt 2 and pRB as this could have implications for the regulation of myogenesis.

In skeletal muscle, it has been shown that Sirt2 negatively regulates insulin resistance in C2C12 cells [32], and induces C2C12 myoblast proliferation by activation of the ERK1/2 pathway [19]. Additionally, there is recent evidence that Sirt2 impacts mitochondrial metabolism and mitophagy $[33,34]$, which is interesting as mitochondria have been implicated in the regulation of processes which occur during myogenesis [34-36], including regulation of myoblast fusion and differentiation.

Several studies have demonstrated that the levels of sirtuin proteins, including Sirt1-3, are downregulated in aged conditions [37-40], and that these decreased levels are associated with several pathological states such as increased ROS accumulation [38], Alzheimer's disease [39], and muscle specific conditions such as sarcopenia [40]. In addition to decreased levels of related sirtuin proteins, overall $\mathrm{NAD}^{+}$levels are decreased in aging which could contribute to a reduction in the functional capacity of these sirtuins [41]. It is known that satellite cell function decreases in aging, and the regenerative capacity of skeletal muscle suffers due to this dysfunction [42]. If Sirt2 plays a role in the regulation of satellite cell mediated myogenesis, it is feasible that the decreased Sirt2 protein levels exhibited in aging may be involved in this dysregulation. Should this be the case, Sirt2 would represent an important potential therapeutic target for the regulation of healthy satellite cell function in aging.

The primary objective of this study is to establish the role of Sirt2 in the myogenic program of muscle satellite cells. The central hypothesis is that Sirt2 expression and deacetylase activity are necessary for the regulation of the differentiation of myoblasts in vitro, therefore, Sirt 2 is required for muscle regeneration and growth. Our rationale for 
conducting this study lies in the structural and functional similarities between Sirt1 and Sirt2 $[12,13,18]$, with the knowledge that muscle-specific inactivation of Sirt1 impairs the myogenic program [10]. In addition to the similarities with Sirt1, the previously characterized roles of Sirt2 in cell cycle regulation, myoblast proliferation, and cellular differentiation suggest that Sirt2 may play a major role in the regulation of myogenesis.

Specific Aim 1: Establish the role and investigate the mechanisms by which Sirt2 mediates myoblast differentiation.

The working hypothesis is that Sirt2 levels and activity are increased during the early differentiation of myoblasts, and the loss of Sirt2 levels inhibit myoblast differentiation, thereby Sirt2 positively regulates the myogenic program.

\section{Specific Aim 2: Investigate the molecular signaling networks through which Sirt2 promotes} myoblast differentiation.

The working hypothesis is that Sirt2 promotes the differentiation of myoblasts by directly targeting and deacetylating cell cycle regulators such as $\mathrm{pRB}$ or E2F1. As a result of these interactions, proliferating myoblasts exit the cell cycle and enter into the differentiation program.

\section{Chapter 2-Background \& Significance}

\section{Satellite Cells}

Skeletal muscle is a highly plastic postmitotic tissue with a high capacity for growth and regeneration [43]. Because adult muscle fibers are terminally differentiated, their regenerative capacity depends on a pool of myogenic stem cells known as satellite cells (SC). SC have acquired their name from their anatomical location, which is between the basal lamina and the sarcolemma 
of myofibers $[1,43]$. SC are mitotically inactive and remain in the G0 phase of the cell cycle until activation $[43,44]$. While SC are usually quiescent [45], upon activation, they contribute to healthy muscle growth (hypertrophy), or muscle repair from injury or disease [46,47].

Under normal conditions, SC express the transcription factor paired-box 7 (Pax7) and remain quiescent [48]. SC are activated in response to various molecular triggers such as exercise, injury, or disease, and they have a remarkable ability to self-renew, expand, proliferate as myoblasts, or differentiate to fuse with and restore damaged muscle [49]. SC are maintained through repeated cycles of growth and regeneration, which is essential for the continued plasticity of skeletal muscle over time. In brief, the activation of SC is characterized by their proliferation as myoblasts, differentiation into myotubes, and subsequent fusion to form new myofibers or supplement existing fibers. This process is known as myogenesis and is regulated by a wide range of proteins within the muscle cells.

\section{Myogenesis}

Studies in the field of skeletal myogenesis [50-52], led to the discovery of the myogenic regulatory factors (MRFs) consisting of MyoD, Myf5, myogenin, and MRF4 (Myf6) [53-56]. Activation of the MRF pathway drives commitment and initiates differentiation along the myogenic lineage. Each member of the MRF family is capable of activating the other members and maintaining its own expression through regulatory networks [57,58]. Collectively, these pathways drive high levels of MRF expression upon activation, which locks the cell into myogenic commitment.

Upon receiving a stimulus for activation (exercise, damage, disease, etc.) quiescent, $\operatorname{Pax} 7^{+}$ SC enter into the cell cycle [59]. For muscle to maintain its regenerative potential, there must be a continual regeneration of SC so once these SC become activated cell fate decisions will specify 
whether the SC self-renews or differentiates. It is known that these activated SC can contribute to regenerating fibers as well as renewing the quiescent SC pool $[60,61]$. This is possible because SC are heterogeneous for Myf5 expression. $\mathrm{Pax}^{+} \mathrm{SC}$ can give rise to both Myf5 ${ }^{+}$and $\mathrm{Myf5}^{-}$cells. $\mathrm{Myf5}^{+}$cells are driven towards myogenic differentiation, while Myf5- cells represent selfrenewing stem cells [44]. MyoD plays a similar role to Myf5 as it also promotes proliferation of SC and the progression of SC towards differentiation. SC expressing MyoD will proliferate as

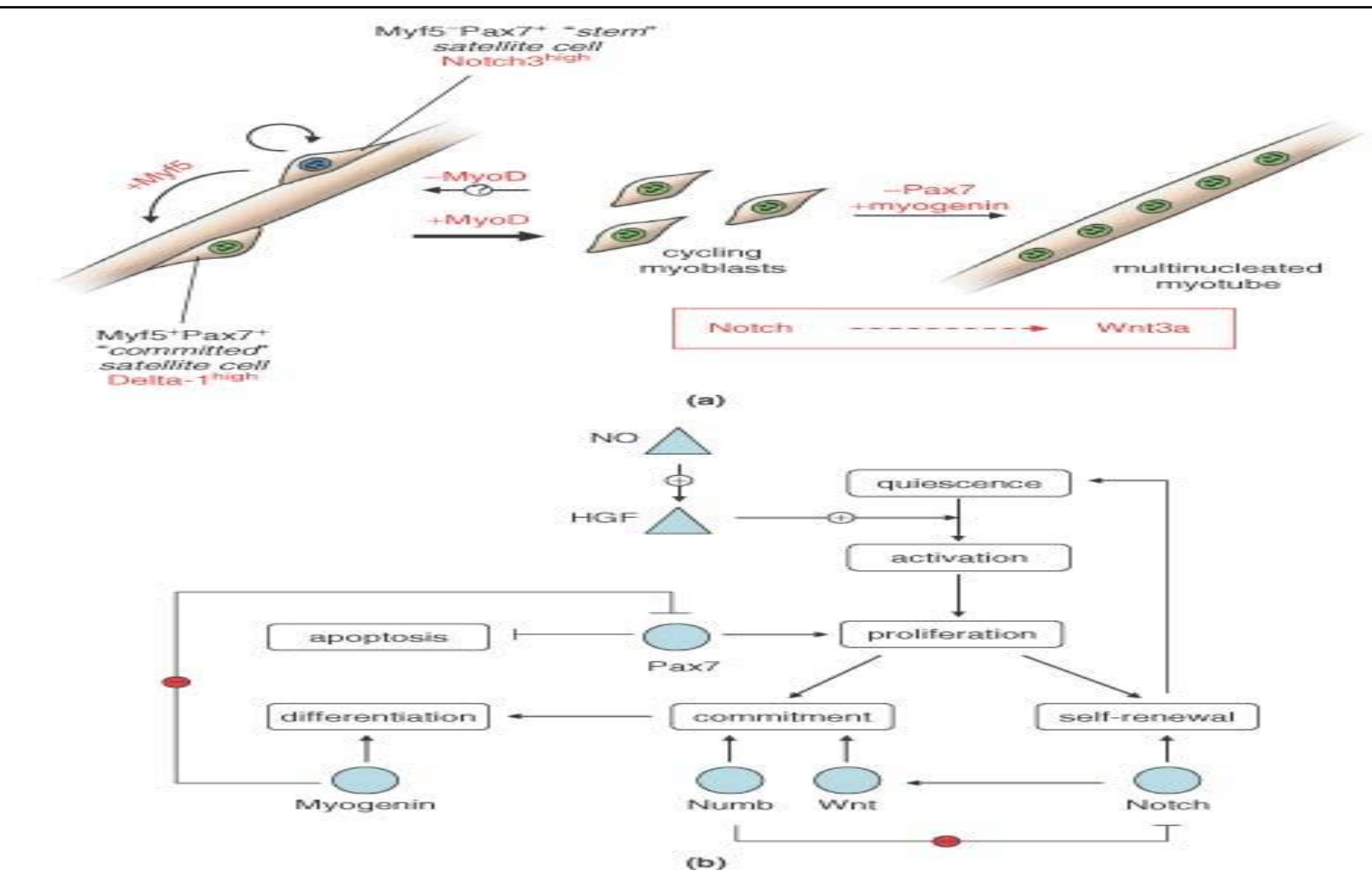

Figure 1: From Punch et al.

myoblasts. These proliferating myoblasts exhibit increased expression and signaling of the cell surface receptor Notch as well as exhibiting $\mathrm{MyoD}^{+}$. This Notch signaling also prevents early activation of MyoD which enhances the proliferative expansion of myoblasts. At this stage of the myogenic program, a transition from Notch signaling to canonical Wnt is required to halt proliferation and initiate terminal differentiation in myoblasts [62].Upon the switch to Wnt signaling the proliferating myoblasts begin to form myotubes. Myotubes are multinucleated fibers 
and can fuse to damaged fibers to assist in repair. During differentiation, myogenin expression is upregulated. Myogenin is required for the fusion of myogenic precursor cells to either new or previously existing fibers [63]. Loss of myogenin results in a nearly complete loss of differentiated muscle fibers and severe loss of skeletal muscle mass [63]. Figure 1 provides an overview of this myogenic signaling.

\section{Sirtuin $1 \& 3$}

There is a keen interest in the Sirtuin family of genes as potential mediators of myogenesis. The Sirtuin family of proteins (1-7) are class III histone deacetylases (HDACs) which require the cofactor NAD+ as a substrate. These proteins are involved in various biological processes including DNA regulation, metabolism, longevity, and myogenesis [10,11,64]. Several members of the Sirtuin family have shown associations with the myogenic program. Among the seven mammalian Sirtuins, Sirt1 is the most characterized and has been reported to regulate various cellular processes such as oxidative stress, cell survival, cell cycling, cell differentiation, and metabolism by deacetylating target molecules [65]. Sirt1 activation with resveratrol treatment has been shown to attenuate the muscular pathology associated with Duchenne muscular dystrophy in the mdx mouse model [66]. Additionally, a study of satellite cells and Sirt1 revealed that mice with muscle-specific inactivation of Sirt1 displayed a decreased regulation of the myogenic program [10]. These Sirt1 deficient mice have reduced myofiber size, exhibit impaired muscle regeneration, and reveal a depression of several muscle developmental genes including MyoD (muscle-specific transcription factor characteristic of activated satellite cells).

Sirt 1 also plays a role in the myogenic differentiation program of $\mathrm{C} 2 \mathrm{C} 12$ myoblasts through its specific recruitment to muscle regulatory regions on chromatin and interaction with a 
MyoD/PCAF complex. This complex then interacts with histone acetyltransferase GCN5, which controls the activity of the myogenic factor MEF2 [67]. These interactions serve to recruit Sirt1 to the histones of these transcription factors and result in deacetylation and subsequent repression of these muscle-specific transcription factors, thereby inhibiting $\mathrm{C} 2 \mathrm{C} 12$ differentiation. In contrast, Sirt1 promotes the proliferation of $\mathrm{C} 2 \mathrm{C} 12$ myoblasts through inhibition of the cell cycle inhibitors, p21 Waf/Cip1 and p27 Kip1 [68].

Sirtuin 3 is located within the mitochondria and is known to deacetylate and activate a large number of mitochondrial enzymes involved in ATP production and in both the citric acid and urea cycles [11]. Similarly to Sirt1, the Sirt3 expression is also increased with caloric restriction in mice [69], and exercise training in mice also increased Sirt3 protein expression within cardiac and skeletal muscle [69]. The Sirt3 expression is also modulated during aging, as characterized by Joseph et al., elderly individuals exhibited a 50\% reduction in PGC-1 $\alpha$ and Sirt3 protein levels in skeletal muscle compared to young subjects, regardless of activity level [70]. By contrast, another study suggested exercise training could maintain Sirt3 levels in the skeletal muscles of both young and aged individuals [71]. The exact mechanisms behind this downregulation of Sirt3 in aging have yet to be full elucidated. A study of the mitochondrial Sirt3 established that Sirt3 is a positive regulator of myogenic differentiation [11], as Sirt3 deficient C2C12 myoblasts exhibited a marked decrease in the myoblast fusion index and a significant reduction of Myogenin, MyoD, Sirtuin 1 and Troponin T protein expression.

\section{Sirtuin 2}

Sirt2, like Sirt1 and Sirt3, are grouped together as class 1 Sirtuins. Considering that both Sirt 1 and 3 have been implicated in myogenesis, we have a considerable amount of interest in Sirt 2 as a potential myogenic effector. Sirt 2 has been detected in many metabolically active tissues 
including the brain, muscle, liver, testes, pancreas, kidney, and adipose tissue of mice [72-74]. Sirt 2 is primarily a cytosolic protein, but it can shuttle between the cytoplasm and the nucleus during the G2/M phase of the cell cycle to deacetylate H4K16 promoting mitotic exit [75]. This translocation appears to happen in response to mitotic stress occurring during the G2/M transition [76]. Additionally, one of the primary functions of Sirt2 is the deacetylation of $\alpha$-tubulin both in vitro and in vivo [77].

The microtubule network is formed by the polymerization of $\alpha$ - and $\beta$-tubulin heterodimers and plays a major role in the regulation of cell shape, intracellular transport, cell motility, and cell division [78]. These tubulin subunits are subject to numerous posttranslational modifications, including tyrosination, phosphorylation, polyglutamylation, polyglycylation, and acetylation [79]. Sirt2 is a predominantly cytoplasmic protein, and it colocalizes with microtubules and deacetylates lysine-40 of $\alpha$-tubulin both in vitro and in vivo, and the knockdown of Sirt2 via siRNA results in tubulin hyperacetylation [77]. Sirt2 has recently been implicated in the regulation of mitophagy through deacetylation of various mitochondrial protein targets [33], which, in addition to cell cycle regulation, provides possible implications in the regulation of myogenesis.

In addition to $\alpha$-tubulin and histone $\mathrm{H} 4$ substrates, Sirt 2 deacetylates forkhead transcription factors of class O, FOXO1, and FOXO3 [80-82]. Given that FOXO transcription factors are involved in multiple cellular processes such as DNA repair, cell cycle, apoptosis, metabolism, and aging, Sirt2 is also connected with these diverse pathways [83].

While primarily cytoplasmic Sirt 2 can translocate to the nucleus and deacetylate H4K16Ac during the $\mathrm{G}_{2} / \mathrm{M}$ phase of the cell cycle, it plays an essential role in cell cycle control [75]. Although some reports suggest Sirt2 tubulin deacetylation might regulate microtubule stability in the mitotic spindle, and thereby control chromosome division [25], various findings demonstrate 
that Sirt2 regulates mitosis through other mechanisms. These mechanisms include deacetylation of $\mathrm{CDH} 1$ and $\mathrm{CDC} 20$ and consequent regulation of anaphase-promoting complex (APC) activity [73], regulation of H4K16 acetylation levels and consequent modulation of PR-SET1 activity and H4K20me1 levels [26], deacetylation and regulation of CDK9 activity [84], and deacetylation and consequent protection from proteasomal degradation of mitotic checkpoint BubR1 [85]. These seemingly strong associations between Sirt 2 and the cell cycle require further elucidation in the context of myogenesis and the cell cycle withdrawal which accompanies myoblast differentiation. To fully understand the myogenic regulation and to apply this information in rehabilitation or recovery of muscle loss from aging and disuse, it is necessary to investigate the possible role Sirt2 may play in this process.

An interesting potential cell cycle target for Sirt2 is the retinoblastoma (RB) protein, which is encoded for by the RB tumor suppressor gene. The RB protein is responsible for a major checkpoint in the G1 phase of the cell cycle in which it blocks S-phase entry and keeps the cells in a G1 growth phase, thereby Sirt 2 promotes terminal differentiation by inducing both cell cycle exit and tissue-specific gene expression [29]. The RB gene family consists of three members, $\mathrm{RB} / \mathrm{p} 105$ (pRb), p107, and RB2/p130, collectively referred to as pocket proteins. This designation stems from the conserved binding pocket region though which $\mathrm{pRB}, \mathrm{p} 107$, and RB2/p130 bind viral oncoproteins and cellular factors such as the E2F family of transcription factors [86], which are recognized as key regulators of cell cycle progression [87], and proliferation-associated genes [88]. The RB family members are active when hypophosphorylated and acetylated on multiple residues [31]. This hypophosphorylated RB is present in resting and early G1 cells and transient phosphorylation of pRB by G1 specific cyclin dependent kinases is the main mechanism by which $\mathrm{pRB}$ activity is regulated [30]. This kinase activity results in the hyperphosphorylation and of $\mathrm{pRB}$ 
and the dissociation of pRB-E2F complexes, enabling E2F-dependent transcription of genes that mediate S-phase entry [29]. In addition to the phosphorylation events acetylation and deacetylation also play important roles in regulating the activity of $\mathrm{pRB}$ and the $\mathrm{pRB} / \mathrm{E} 2 \mathrm{~F}$ complex. Acetylation of $\mathrm{pRb}$ occurs at the C-terminus by $\mathrm{p} 300$, a member of the $\mathrm{p} 300 / \mathrm{CBP}$ (cAMP-response-elementbinding protein-binding protein) family of HAT (histone acetyltransferase) transcriptional coactivators [89]. This acetylation obstructs the phosphorylation of $\mathrm{pRB}$, leading to the maintenance of $\mathrm{pRB}$ in its active hypophosphorylated form. Once activated the RB proteins inhibit the activity of the E2F transcription factors, which mediates cell cycle exit and, in the case of muscle, the expression of late myogenic genes including MyHC [90]. The deacetylation of pRB by HDAC proteins allows the phosphorylation of $\mathrm{pRB}$ by the cyclin dependent proteins resulting in the inhibition of $\mathrm{pRB}$ and the progression of the cell cycle. Sirt1 has the ability to deacetylate $\mathrm{pRB}$ and thus promotes the inactive hyperphosphorylated form of pRB [31]. The interaction between the $\mathrm{RB}$ family proteins and the $\mathrm{E} 2 \mathrm{~F}$ family transcription factors plays a central role in governing cell cycle progression and DNA replication by controlling the expression of cell cycle E2Fdependent genes, [91], and Sirt1 has been implicated in this regulation as an RB specific deacetylase [31], increasing the interest in related HDAC involvement in this process.

The RB mediated repression of E2F transcription factors may be linked to the recruitment of chromatin remodeling enzymes, including HDACs $[92,93]$. The $\mathrm{pRB}$ is able to form a complex with the HDAC [94], which can then interact with the E2F promoter and inhibit gene expression by blocking the access of transcription factors to the promoter [95]. Experiments in vitro have supported this possible interaction and shown that HDAC is required for the inhibition of E2F by RB [94], while other studies have shown only a partial requirement for HDAC activity in the RBmediated inhibition of E2F [96]. To facilitate the binding and interaction, both pRB and HDAC1 
possess a conserved LXCXE motif which allows them to bind and form the complex that ultimately silences E2F1 transcription [94,97] E2F1 has been shown to interact with the histone acetyl transferases p300/CBP and p/CAF [98], so it is possible that $\mathrm{RB}$-mediated recruitment of HDAC to E2F acts to offset this histone acetyltransferase (HAT) activity. It has also been shown recently that E2F1 can be acetylated, which increases the binding of the E2F/DP complex to DNA [99]. Therefore, recruitment of HDAC to E2F via RB may inhibit E2F activity by deacetylation and inhibit its binding to DNA. This mechanism suggests there may be a potential link between Sirt2 and the RB protein in the process of cell cycle regulation, which is further supported as there is growing evidence that RB has regulatory effects on the cell cycle beyond G1[92], which

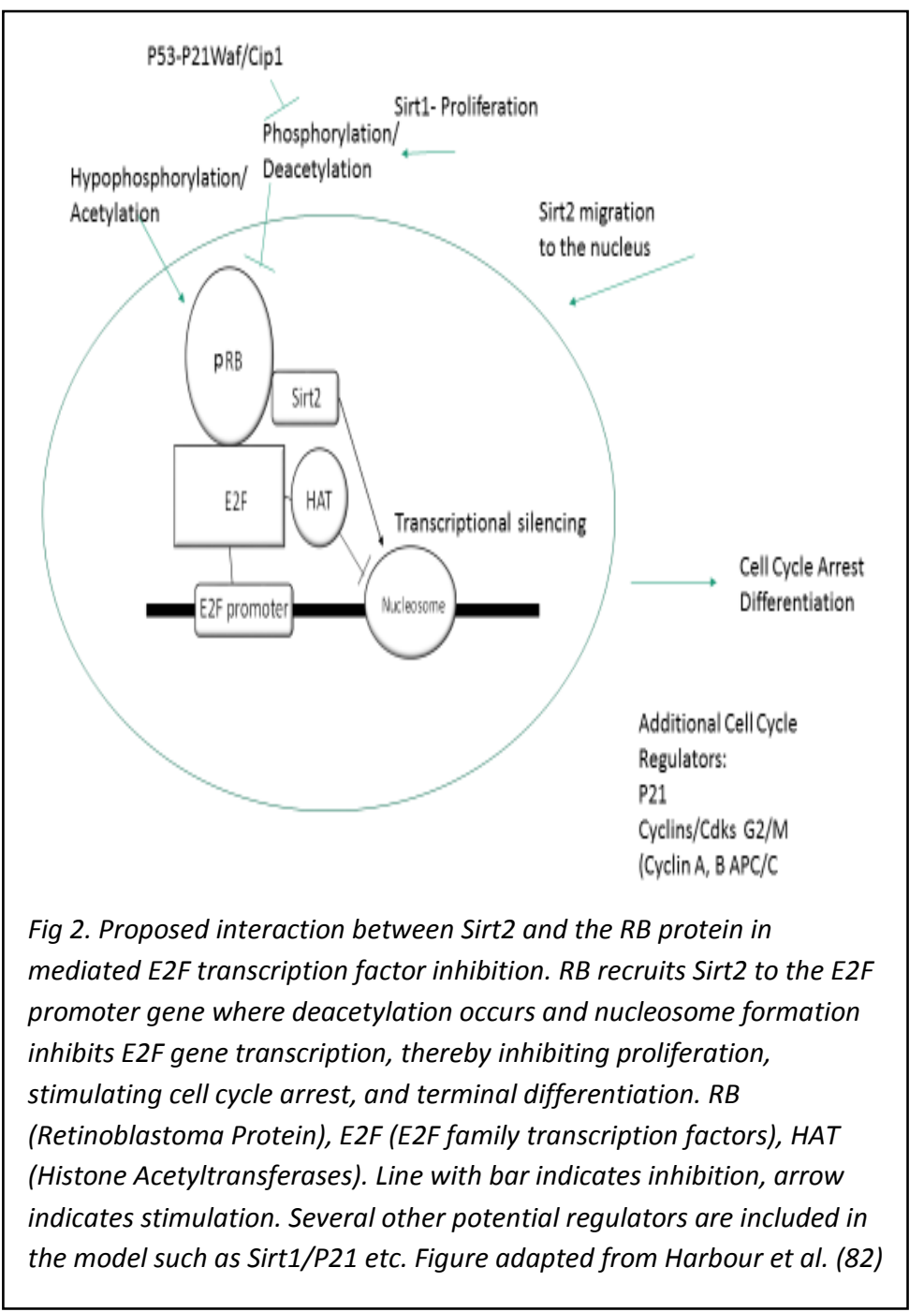
could bring RB into contact with Sirt2 when it enters the nucleus during G2. One proposed pathway for Sirt2 and RB action is depicted in figure 2, in which Sirt2 forms a complex with RB family proteins such as $\mathrm{pRB}$ and is recruited to E2F family transcription factors to aid in their inhibition. This process is likely to occur early in the differentiation program when Sirt2 is upregulated (12, 24 hours), coinciding with increased MyoD expression. The combined action of Sirt2 and RB will contribute to cell cycle arrest and terminal differentiation. 
Overexpression of all three pocket proteins in cells can induce growth arrest in the G1 phase of the cell cycle linked to the upregulation of the cell cycle inhibitor p21 and the repression of E2F regulated proliferative genes [100]. This revelation helped to define the role of the RB gene family in regulating transition between cell proliferation and terminal differentiation [86]. Following this acute growth arrest, a more permanent cell cycle withdrawal is considered necessary for the later stages of differentiation. This then renders myotubes conducive to the expression of late markers including MyHC [90]. Thus, pRB fills a more accurate role throughout the later phases of myogenesis.

The $\mathrm{pRb}$ protein also has a central role in various differentiation processes including the nervous system, liver, and muscle tissue. For example, pRB is necessary for the completion of the muscle differentiation program and myogenic helix-loop-helix dependent transcription [101]. This regulation involves a transcriptional link between $\mathrm{pRB}$ and MyoD over the course of myogenesis. It has been demonstrated that expression of $\mathrm{pRB}$ can upregulate MyoD transcriptional activity and induce the expression of late muscle differentiation markers such as myosin heavy chains (MHC) and muscle-specific creatine kinase [102]. In pRB -/- mouse embryonic fibroblasts (MEFs) the 2 remaining RB family members, p107 and p130, can partially augment MyoD transcriptional activity and upregulate expression of $\mathrm{MyHC}$ and MCK, but functional $\mathrm{pRB}$ is required for their full induction [103].

Recently, is was shown that Sirt2 interacts directly with mitochondrial proteins and helps to shape mitochondrial metabolism [33]. Direct electron microscope images support that Sirt2 associates with the inner mitochondrial membrane and the loss of Sirt2 increases oxidative stress, and dysregulates mitophagy through the loss of direct deacetylation of ATG5 by Sirt2. Mitochondrial function and activity are linked to cell differentiation, as has been shown in a wide 
variety of cell types including myoblasts [36,104,105]. When myoblasts differentiate into myotubes, mitochondrial enzyme activity is drastically increased [106,107], suggesting a metabolic shift from glycolysis to oxidative phosphorylation during this time.

\section{Chapter 3 - Research Design, Methods, and Procedures}

\section{Research Design}

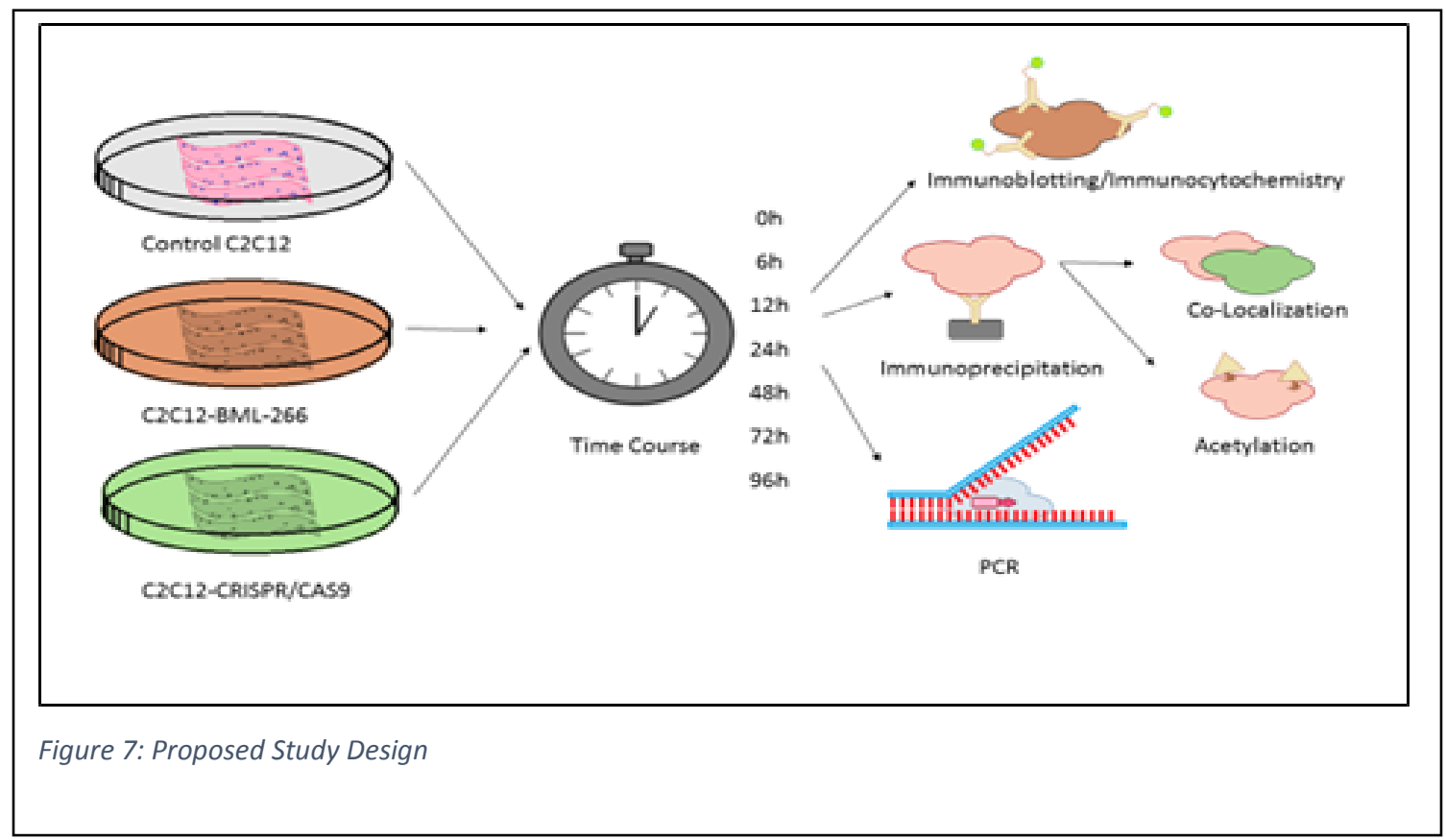

The general study design is shown in figure 7. The model used C2C12 mouse myoblasts

to examine the regulation of Sirt2 during myogenesis. The cells were subjected to several conditions and samples were taken from control C2C12 cells, cells which were supplemented with the Sirt2 deacetylase inhibitor BML-266, and a group which was transfected with a Sirt2 KO CRISPR/CAS9 plasmid and control plasmid. These myoblasts were cultured in growth media and used for the various assays (immunoblot, immunocytochemistry, immunoprecipitation, etc.) that were necessary for the study. Certain assays required the myoblasts to be transferred to a differentiation medium to induce serum starvation promoting the differentiation of the myoblasts 
into myotubes. Cell samples were taken at various time points ranging from 0 hours to 96 hours, and these time points encompass both myoblasts (early time points) and myotubes (later time points). Samples from these various time points were used to generate a model of Sirt2 regulation during myogenesis in support of specific aim 1.

For specific aim 2 various protein targets of interest were examined using immunoprecipitation assays, immunoblotting, and probing for acetylation status. These assays were used to determine the specific proteins that interact with Sirt2 at the various time points during myogenesis. Proteins which interact with Sirt2 in immunoprecipitation assays were subsequently evaluated with acetylated lysine antibodies to assess the acetylation status of these proteins. The various protein targets included myogenic proteins such as Pax7, MyoD, and myogenin. In addition to these myogenic proteins, we focused cell cycle markers such as the retinoblastoma protein $\mathrm{Rb} / \mathrm{p} 105$ (pRb). These data were used to form the proposed regulatory model in which Sirt2 promotes the differentiation of $\mathrm{C} 2 \mathrm{C} 12$ myoblasts through interactions with cell cycle associated proteins and the deacetylation mechanism inherent to Sirt2.

\section{Methods}

\section{Cell Culture}

C2C12 mouse skeletal muscle myoblasts were cultured in Dulbecco's Modified Eagle Medium (DMEM). The proliferation media or growth media (GM) consisted of 500ml of DMEM, $50 \mathrm{ml}$ of fetal bovine serum (10\%), and $6 \mathrm{ml}$ of antibiotic/antimycotic (GIBCO, Invitrogen, 15240) (1\%). The differentiation media (DM) consisted of 500ml of DMEM, 10ml of horse serum (2\%), and $5 \mathrm{ml}$ of A/A (1\%). Cells were subcultured when confluency reached $70-80 \%$. The plates were washed with warm 1x PBS and the cells were dislodged by 1x trypsin treatment. The cells were cultured in $10 \mathrm{~cm}$ plates and terminal differentiation was induced when the cells approached 70- 
$80 \%$ confluence. All cells were cultured in an incubator at $37^{\circ} \mathrm{C}, 5 \% \mathrm{CO} 2$, and $95 \%$ humidity. All cell culture was conducted within a sterile culture hood which was subjected to 30 minutes of ultraviolet light both before and after working with samples within the hood. The working surface of the hood was also cleaned with $70 \%$ ethanol both before and after working with samples.

\section{Differentiation}

The myoblasts were cultured and placed in differentiation medium upon reaching approximately $70-80 \%$ confluency. Differentiation was induced via serum starvation in a differentiation medium (DMEM, 2\% horse serum, 1\% AA) and subsequently myoblasts and myotubes were collected at different time points throughout myogenesis. Cells were collected at $0,12,24,48,72$, and 96 hours. Various assays were conducted with the myoblasts/myotubes at each time point including protein and immunocytochemical analysis. The cells were collected and stored at $-80^{\circ} \mathrm{C}$ until needed for assays. In brief, collected cells were first washed with warm $1 \mathrm{x}$ PBS to remove the media. The plates were then placed on ice and cell scrapers were used to collect the samples which were then placed into $15 \mathrm{~mL}$ tubes. The collected cells and PBS were centrifuged at $4^{\circ} \mathrm{C}, 700 \mathrm{G}$, for 5 minutes. The cell pellets were then transferred to $1.5 \mathrm{~mL}$ tubes, and the supernatant (PBS) was removed and the pellets were frozen at $-80^{\circ} \mathrm{C}$ for use in subsequent assays.

\section{Differentiation Assay/ Immunocytochemistry}

Differentiation was induced in C2C12 myoblasts by serum withdrawal (DMEM, 2\% horse serum, $1 \%$ AA) and this differentiation was then evaluated by immunofluorescence. The cells used were fixed on gelatin coverslips with 1:1 acetone methanol for 10 minutes at $4^{\circ} \mathrm{C}$. These coverslips were then used for subsequent immunocytochemistry. After blocking the coverslips in $1 \%$ normal goat serum at RT for 1 hour the cells were first stained with an antibody for non-specific myosin 
heavy chain (mf20, Developmental Studies Hybridoma Bank, University of Iowa). Primary antibodies were diluted in sterile PBS at a concentration of 1-100 and incubated with the cells at $4^{\circ}$ overnight. Following primary antibody incubation a fluorescent secondary antibody (Alexa Fluor 488 goat anti-mouse $\operatorname{IgG} 2 \mathrm{~b}$ ) at a concentration of 1-500, the differentiation index was calculated by counting the number of nuclei, stained with 4',6-Diamidino-2-Phenylindole, Dihydrochloride (DAPI, Molecular probes by Life Technologies,), in a series of 5 pictures taken from each sample. Myotubes with more than 2 nuclei per fiber were counted as differentiated nuclei incorporated into myotubes. The differentiation index was calculated as the number of nuclei in differentiated cells/total number of nuclei. This differentiation index or myotube fusion index was performed with control $\mathrm{C} 2 \mathrm{C} 12$ myoblast cells, cells which were incubated with varying concentrations of BML-266 $(1 \mathrm{uM}, 2 \mathrm{uM}, 2.5 \mathrm{uM}, 3 \mathrm{uM})$ and cells which were transfected with CRISPR/CAS9 knockdown and control plasmids.

\section{Western Blot Analysis}

Protein lysates from the samples that were collected from culture timepoints were extracted using a RIPA (50mM Tris-cl pH 7.4, 150mM NaCl, $1 \%$ NP40, 0.25\% Na-deoxycholate) lysis buffer supplemented with $10 \mathrm{uL}$ sodium metavanadate, $1 \mathrm{uL}$ Dithiothreitol, $10 \mathrm{uL}$ of protease inhibitor cocktail (Sigma \#8340), and $10 \mathrm{uL}$ of phenylmethane sulfonyl fluoride for every $1 \mathrm{~mL}$ of RIPA buffer. The Coomassie Blue (Bradford) protein quantification assay was conducted to acquire the protein concentrations for samples before gel electrophoresis. Loading samples generated for Western Blot contained $25 \mu \mathrm{g} / \mu \mathrm{L}$ of protein for each sample run. $30 \mu \mathrm{L}$ of working solution (Protein lysate of $25 \mathrm{ug}, 1 / 3$ volume $4 \mathrm{x}$ sample dye, $1.5 \mathrm{uL}$ DTT, and ddH2O to volume of 30uL) was subjected to gel electrophoresis in 4-12\% bis-tris (NuPage) gel at 150 volts in MES running buffer $(950 \mathrm{~mL}$ ddH2O, 50mL MES running stock solution, NOVEX by Life 
Technologies). The gel was then transferred to a nitrocellulose membrane at $4^{\circ} \mathrm{C}$ for 1 hour at $30 \mathrm{~V}$ in transfer buffer $(850 \mathrm{~mL}$ ddH2O, $100 \mathrm{~mL}$ methanol, $50 \mathrm{~mL}$ stock transfer solution, NOVEX by Life Technologies). The membranes were then cut at various molecular weights to isolate specific proteins and blocked in $2 \%$ nonfat milk blocking solution for 1 hour prior to incubating overnight with gentle rocking at $4{ }^{\circ} \mathrm{C}$ in appropriate antibodies, Cell Signaling: (p21 Waf1/Cip1), (Ac-alphaTubulin), (Ac-Lysine), (Sirt3), (Lamin B1), Millipore: (Sirt1), (Sirt2), Thermo Scientific: (RB), (E2F1), BD Pharmingen: (MyoD), Santa Cruz Biotechnology, (Myogenin), (PGC1 $\alpha$ ), Abcam: (cyclophilin). Following overnight incubation, membranes were washed $3 \mathrm{x}$ in TBST for 5 minutes each. After washing, secondary antibodies in $2 \%$ nonfat milk blocking solution were applied to the membrane and allowed incubation at room temperature for 1 hour. Membranes were then washed $4 \mathrm{x}$ for 15 minutes before exposing the membranes using SuperSignal West Dura extended duration substrate (Thermo Scientific) for subsequent chemiluminescent detection of antibodies using a Syngene GBOX Chemiluminescence and Fluorescence Imaging System.

\section{Nuclear/Cytosolic Fractionation}

Cells collected at various time points as described previously were used for cytosolic and nuclear fractionation. Cell pellets were homogenized on ice in $200 \mathrm{uL}$ of ice cold lysis buffer $(10 \mathrm{mM} \mathrm{NaCl}, 1.5 \mathrm{mM} \mathrm{MgCl} 2,20 \mathrm{mM}$ HEPES, $20 \%$ glycerol, $0.1 \%$ Triton $\mathrm{x}-100,1 \mathrm{mM}$ dithiothreitol, $\mathrm{pH}$ 7.4). The homogenates were centrifuged at $1,000 \mathrm{rpm}$ for 1 minute at $4^{\circ} \mathrm{C}$, and subsequently, the supernatants were collected containing the cytoplasmic extracts. Protease inhibitor cocktail (Sigma \#8340) was added to these samples. After collecting the cytoplasmic extract, the remaining nuclear pellet was suspended in $100 \mathrm{uL}$ of lysis buffer, and $11 \mathrm{uL}$ of $5 \mathrm{M}$ $\mathrm{NaCl}$ was added to lyse the nuclei. This mixture was then rocked for $2 \mathrm{~h}$ at $4^{\circ} \mathrm{C}$ and subsequently centrifuged at $14,000 \mathrm{rpm}$ for 15 minutes at $4^{\circ} \mathrm{C}$. The resulting supernatant was collected 
containing the nuclear fraction and protease inhibitor cocktail was added to these samples. These collected samples were then used for western blot analyses.

\section{Transfection of CRISPR/CAS9 Plasmids}

C2C12 myoblasts were transfected with CRISPR/Cas9, GFP (Santa Cruz Biotechnology) plasmids to create Sirt2 knockdown and control plasmid cell lines. Cells were seeded in 6-well plates and grown to $40 \%$ confluency. At this time the cells were incubated in $3 \mathrm{ml}$ of antibiotic free standard growth media per well 24 hours before the transfection. Plasmid DNA was transfected at lug per well with 10ul of transfection reagent media as described in the Santa Cruz protocol for CRISPR transfection. After 24 hours the antibiotic free media was replaced with normal growth media containing $1 \%$ antibiotic/antimycotic. Transfection efficiency was visually confirmed by detection of the green fluorescence protein (GFP) via fluorescent microscopy. GFP positive cell lines were then isolated via FACS cell sorting to create pure cell lines. These isolated cells (GFP positive) were then sub-cultured to create a population of stably transfected cells which were used for a variety of assays.

\section{FACS-Cell Sorting}

CRISPR-CAS9 transfected cells were isolated and collected from 6-well plates. The cells were homogenized in sorting buffer (1x PBS, 2.5mM EDTA, 1\% FBS, 25mM HEPES, pH 7.0) and sorted using a FACS Aria cell sorter at the WVU flow cytometry core. Cells were then isolated into two populations (Sirt2 knockdown, control plasmid) via the GFP tag incorporated into the plasmids. Sorted cells were then plated and grown for subsequent assays via normal cell culture protocol.

\section{Immunoprecipitation}


Each collected protein sample was first pre-cleaned and incubated with $25 \mu \mathrm{L}$ of homogenized protein $\mathrm{A} / \mathrm{G}$ beads (Invitrogen) for 1 hour with rotation at $4{ }^{\circ} \mathrm{C}$. Beads were then separated from protein using a magnetic separator. The supernatant volume was then increased to $500 \mu \mathrm{L}$ using lysis buffer and $2 \mathrm{ug}$ of primary antibody were added to each sample $(\mathrm{Rb} 1$, Thermo Fisher Scientific). The antigen and antibody solution was then incubated for 2 hours at $4^{\circ} \mathrm{C}$ with rotation. New magnetic protein A/G beads will be cleaned 3x using wash buffer (Tris Buffered Saline containing $0.05 \%$ Tween-20 detergent and $0.5 \mathrm{M} \mathrm{NaCl}$ ). Antigen and antibody solution was then added to clean $\mathrm{A} / \mathrm{G}$ beads and allowed overnight incubation with rotation at $4^{\circ} \mathrm{C}$. Beads were then separated using a magnetic separator and the flow through was saved for analysis. The magnetic beads were washed $3 \mathrm{x}$ in $500 \mu \mathrm{L}$ of IP wash buffer for 30 minutes with rotation. A single wash of $500 \mu \mathrm{L}$ of distilled $\mathrm{H}_{2} \mathrm{O}$ followed the wash with IP wash buffer to release the collected protein from the beads. These beads were then collected by the magnetic apparatus and the water supernatant was discarded. Next $30 \mu \mathrm{L}$ of $1 \mathrm{x}$ sample buffer $(8 \mathrm{uL} 4 \mathrm{x}$ NuPAGE LDS sample buffer, $21 \mathrm{uL}$ cell lysis buffer, 2.8uL DTT) were loaded to each tube of beads and heated at $70^{\circ} \mathrm{C}$ for 10 minutes. The beads were then separated and discarded while the flow through was loaded into 4-12\% bis-tris gel and a Western Blot protocol was performed on the pull-down. Real-Time PCR-

Total RNA was isolated from the cells using an RNeasy min kit and then treated with DNase I. First-strand cDNA was synthesized from $1 \mu \mathrm{g}$ total RNA by reverse transcription in a 20- $\mu$ l reaction using a SuperScript III RT first-strand cDNA synthesis kit (Invitrogen). Primers for Sirt1-7 were used with a concentration of 10uM;

Invitrogen primers:

Mus musculus sirtuin 1 (NM_001159589) 
Sirt1 F: ATGACGCTGTGGCAGATTGTT

Sirt1 R: CCGCAAGGCGAGCATAGAT

Mus musculus sirtuin 2 (NM_001122766)

Sirt2 F: CCACGGCACCTTCTACACATC

Sirt2 R: CACCTGGGAGTTGCTTCTGAG

Mus musculus sirtuin 3 (NM_001127351)

Sirt3 F: $\quad$ CTGACTTCGCTTTGGCAGAT

Sirt3 R: GTCCACCAGCCTTTCCACAC

Mus musculus sirtuin 4 (NM_001167691)

Sirt4 F: GTGGAAGAATAAGAATGAGCGGA

Sirt4 R: GGCACAAATAACCCCGAGG

Mus musculus sirtuin 5 (NM_178848).

Sirt5 F: GCAGACGGGTTGTGGTCAT

Sirt5 R: CTGGGCAGATCGGACTCCTA

Mus musculus sirtuin 6 mRNA (NM_181586)

Sirt6 F: TCGGGCCTGTAGAGGGGAGC

Sirt6 R: CGGCGCTTAGTGGCAAGGGG

Mus musculus sirtuin 7 mRNA (NM_153056)

Sirt7 F: CAATCCTGTGTTTAGGGTCCAG

Sirt7 R: $\quad$ GTTCACGATGTAGAGTTTGGGTC

Mus musculus GAPDH

F: $\quad$ GAAGGTGAAGGTCGGAGTCA

R: $\quad$ TGGAAGATGGTGATGGGATT

GAPDH (glyceraldehyde 3-phosphate dehydrogenase) primers were utilized as internal controls. Ambion DNase1 (Cat\#AM2222) was used to purify the samples of genomic DNA. Real-time PCR (qPCR) was performed in a Mx3005P qPCR system using Brilliant SYBR green qPCR Master Mix according to the manufacturer's procedures (Bioline).The amount of mRNA transcripts $\left(2^{-\Delta} \mathrm{CT}\right)$ were estimated by the comparative $\mathrm{CT}(\Delta \mathrm{CT})$ method and normalized to an endogenous reference (GAPDH) relative to a calibrator.

\section{Statistics}


The data are presented as means \pm SEM and multiple t-tests were used to assess statistical significance with $\mathrm{p}<0.05$. All test were run in triplicate.

\section{Chapter 4 - Results}

\section{Specific Aim 1: Establish the role and investigate the mechanisms by which Sirt2 mediates} myoblast differentiation.

The working hypothesis is that Sirt2 levels and activity are increased during the early differentiation of myoblasts, and the loss of Sirt2 levels inhibit myoblast differentiation, thereby Sirt2 positively regulates the myogenic program.
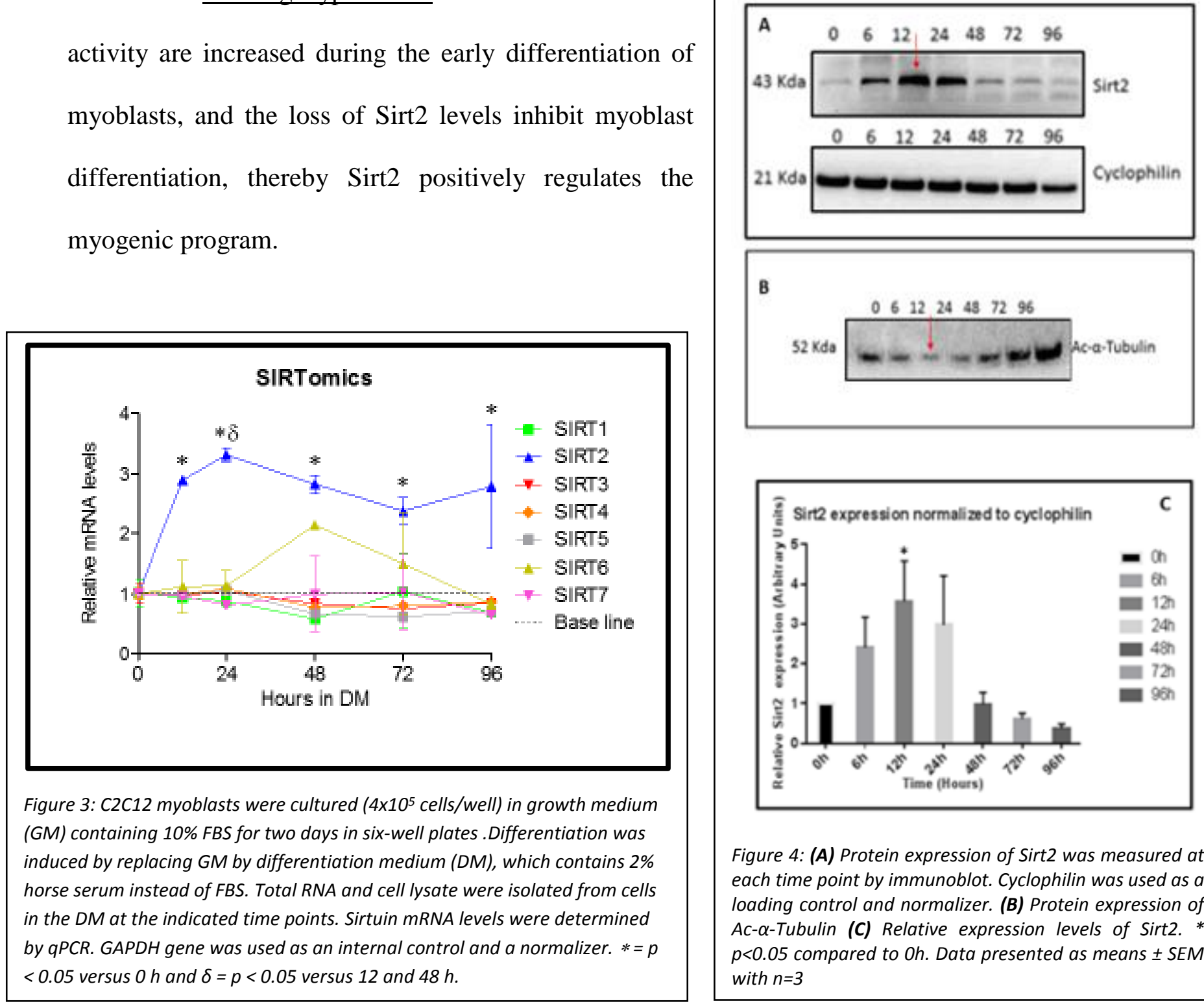

Figure 4: (A) Protein expression of Sirt2 was measured at each time point by immunoblot. Cyclophilin was used as a loading control and normalizer. (B) Protein expression of Ac- $\alpha$-Tubulin (C) Relative expression levels of Sirt2. * $p<0.05$ compared to Oh. Data presented as means \pm SEM with $n=3$ 
The levels of sirtuin (1-7) mRNA were quantified using qPCR (Fig. 3). GAPDH was used as the internal control and for normalization. The relative expression of Sirt2 mRNA was significantly increased at several time points that were measured after the induction of differentiation by
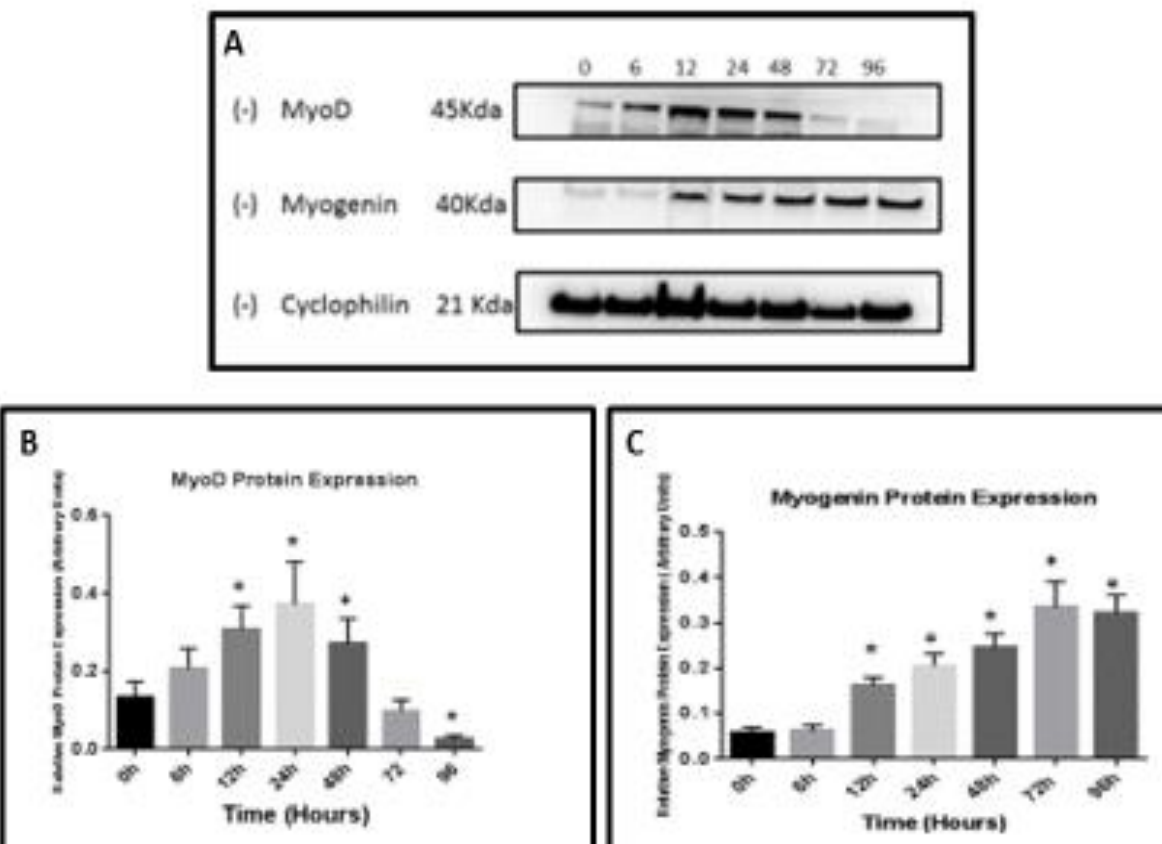

Figure 5: Protein expression of muscle transcription factors. (A) Representative immunoblot images of MRF proteins MyoD and Myogenin. (B-C) Quantification of the relative protein expression levels of $M y o D$ and Myogenin normalized to cyclophilin. The * represents a significant difference from the $\mathrm{Oh}$ time point with $p<0.05$. The data are presented as means \pm SEM with $n=3$.

serum starvation. The levels of the other sirtuins remained fairly consistent throughout the time course. Examining western blot assays for wild type C2C12 cells subjected to the $0-96 \mathrm{~h}$ time course, we observed a transient increase, then subsequent decrease in Sirt2 protein expression during C2C12 myoblast differentiation via immunoblotting (Fig. 4). This transient increase in Sirt2 protein expression is significantly increased at the $12 \mathrm{~h}$ time point and is

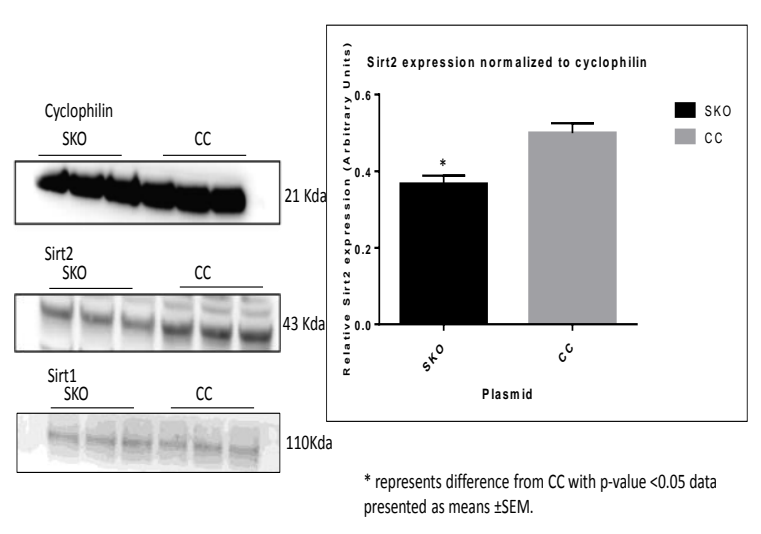

Figure 6a: Immunoblot of Sirt2 protein levels after transfection with a Sirt2 knockdown CRISPR/CAS9 plasmid. * represents a significant difference from $C C$ with the $p$-value $<0.05$. The data are presented as means \pm SEM with $n=3$. 
elevated at the $24 \mathrm{~h}$ time point as well. This trend remained constant over the course of our experimentation, with many sample groups supporting this differential Sirt2 protein regulation during the early stages of myoblast differentiation. The expression of Acetylated- $\alpha$-Tubulin was also measured and was decreased at the $12 \mathrm{~h}$ time point, corresponding to the increased Sirt 2 level. As Acetylated- $\alpha$-Tubulin is a deacetylation target of Sirt2 this suggest Sirt 2 is active at the $12 \mathrm{~h}$ time point. The protein expression levels of myogenic transcription factors were also measured (Fig. 5). MyoD expression increased during the early stages of myogenesis and was significantly increased at the $12 \mathrm{~h}$ and $24 \mathrm{~h}$ time points. This expression coincides with the transient increase in Sirt2 expression that was previously observed. This MyoD expression was then observed to decrease as the expression of myogenin was increased. Myogenin is necessary for the

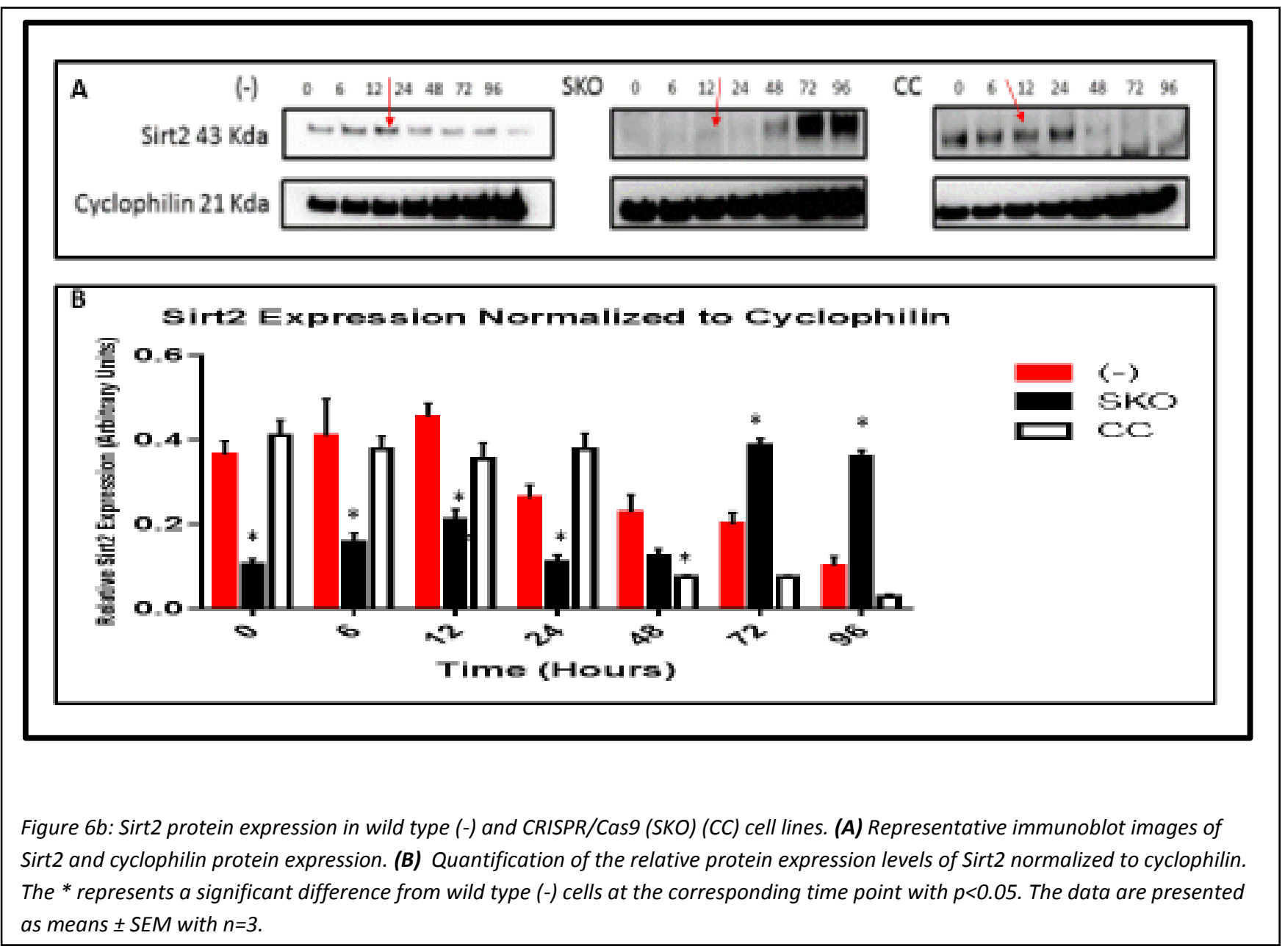


differentiation and fusion of myoblasts, and the induction of myogenin at these time points coincides with the formation of myotubes in the $\mathrm{C} 2 \mathrm{C} 12$ cells.

In order to elucidate the mechanism/s by which Sirt 2 regulates the differentiation of myoblasts, we inhibited Sirt 2 both pharmacologically using the Sirt2 inhibitor (BML-266), which impairs the deacetylase activity of Sirt2 without knocking down its protein expression [67], and also knockdown of Sirt2 protein expression using a CRISPR/Cas9 plasmid (Fig. 6a). The expression of Sirt2 was significantly decreased following transfection of the CRISPR/Cas9 knockdown plasmid. Sirt2 knockdown in the SKO cells was not observed in the cells transfected with the CRISPR/Cas9 control plasmid, and Sirt1 levels also remained consistent between the groups. The protein expression of Sirt2 was also measured over the time course of myogenesis in the wild type and

\section{Immunocytochemistry 96h} A
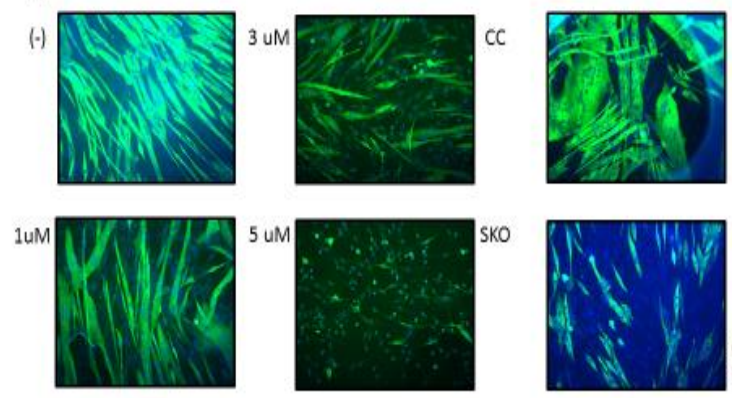

en: Mf20-MyHC Blue: DAPI nuclear sta
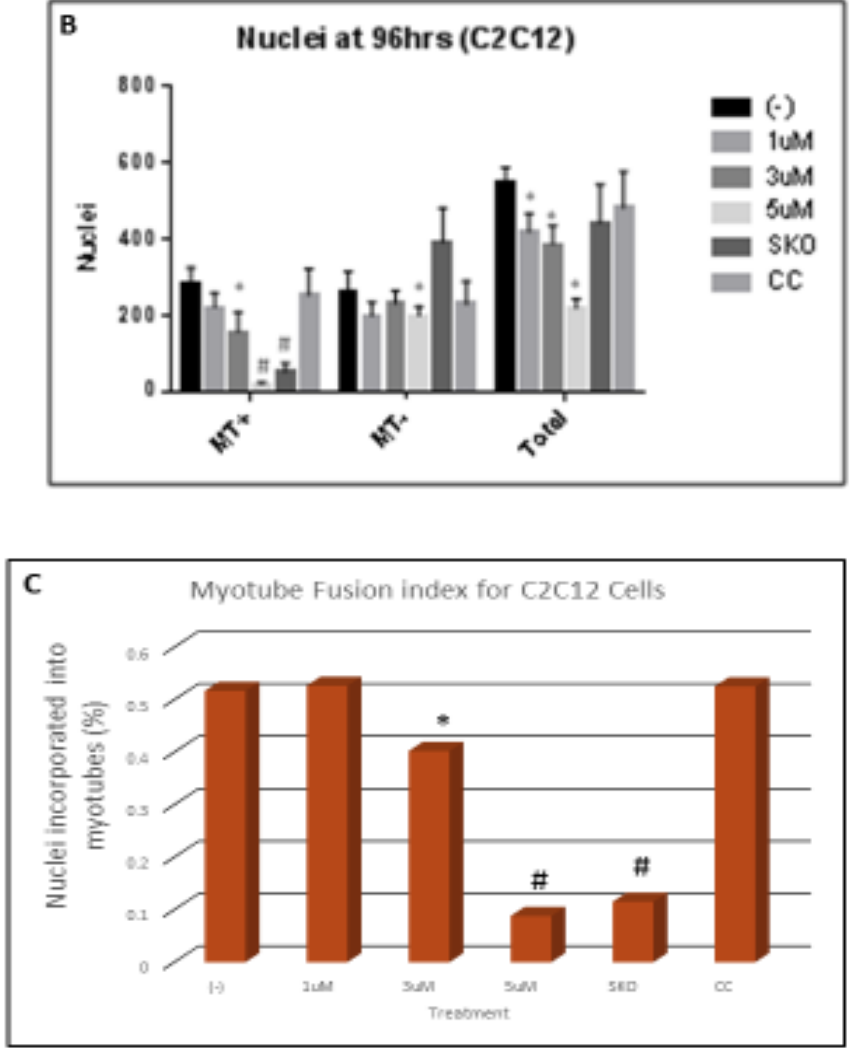

Figure 7: (A) Immunocytochemistry for $\mathrm{C2C12}$ cells of each cell group, (-), SKO, CC at 96h. The panels show representative images at the $96 \mathrm{~h}$ time point. The cells are stained with an antibody for non-specific myosin heavy chain (mf20 green), and overlaid with DAPI nuclear stain. (B) MT+ represents the amount of nuclei incorporated into myotubes. MTrepresents the number of nuclei which were not incorporated into myotubes. (C) calculation of the myotube fusion index: MT+/Total nuclei. Data were collected by counting nuclei from 5 representative images (20x) of myotubes cultures on coverslips. * represents difference from (-) with $p$ value $<0.05$. $\#<0.01$ and presented as means \pm SEM 
CRISPR/Cas9 groups (Fig. 6b). The observed protein expression for Sirt2 was significantly reduced at several time points in the SKO group. However it was significantly increased at later time points (72h and 96h). The Sirt2 expression levels in the (-) and CC groups were not significantly different.

The onset of myoblast differentiation could represent a critical point for Sirt2 guided regulation of myogenesis, and we have demonstrated that inhibition of Sirt2 via BML-266 and CRISPR/CAS9 knock down, results in a decrease in myotube formation (Fig. 7). The observed numbers of nuclei incorporated into myotubes (defined as a cell having a minimum of 3 nuclei), were significantly decreased in the 3uM and 5uM BML-266 groups, and in the SKO Sirt2 knockdown group. The total number of nuclei observed was significantly decreased in all

\section{Myotube Fusion-Inhibition of Sirt2 with BML-266 at 96h}

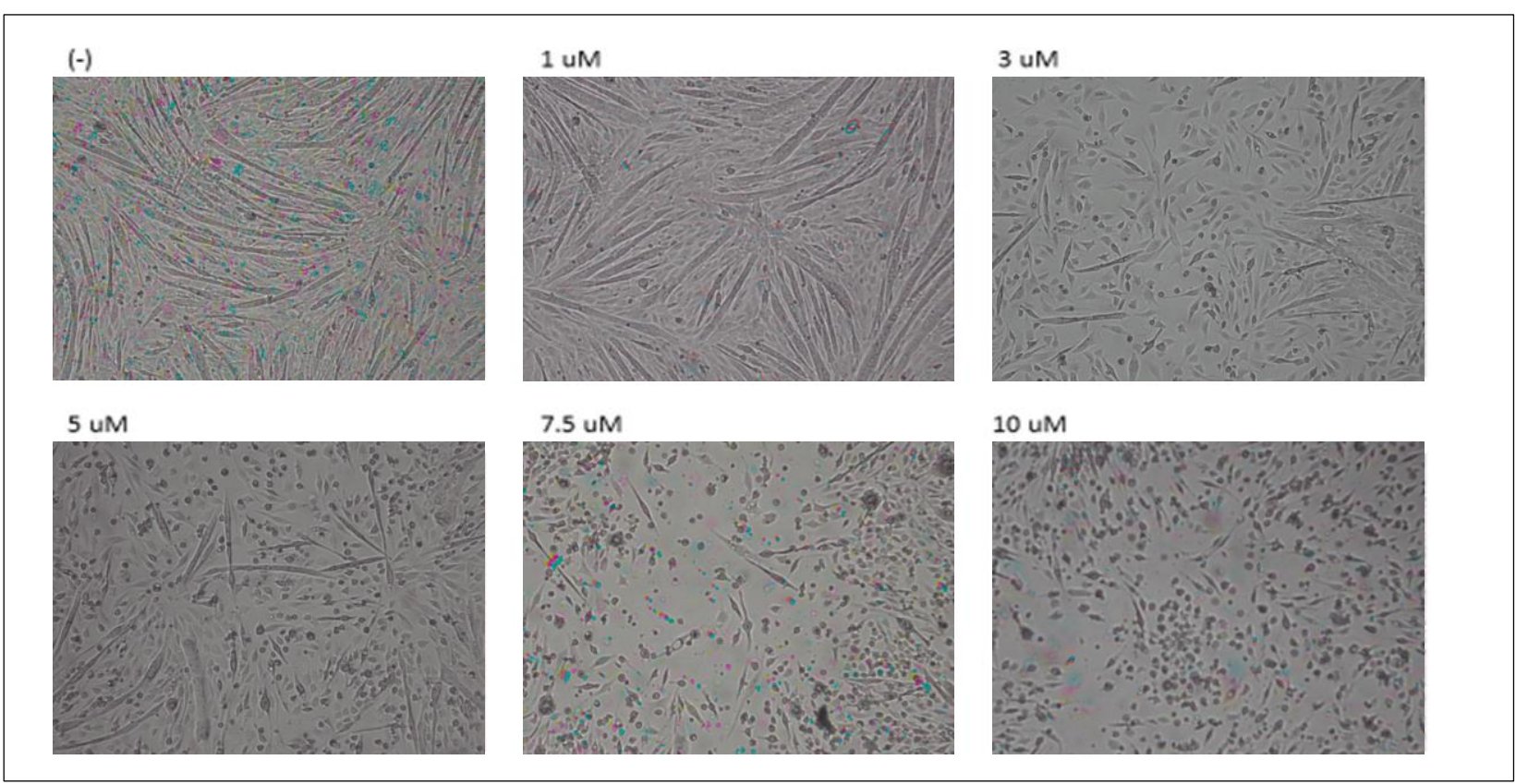

Figure 8: Representative C2C12 myotubes following 96 hours of differentiation in the presence of various concentrations of the Sirt2 deacetylase inhibitor BML-266. These data show that with increasing concentrations of BML-266 the formation of myotubes becomes progressively worse. At very high concentrations (7.5-10uM) there is large amounts of apoptosis and the cells appear small and unhealthy. In addition to the decrease in total nuclei observed in the myotube fusion indices this apoptosis and general unhealthy cell state may indicate non-specific cytotoxicity in the pharmacologically treated groups. 
pharmacologically treated groups, but not in the CRISPR/Cas9 cell groups. This suggests that there could be non-specific cytotoxic effects occurring in the pharmacologically treated groups which must be taken into account when interpreting these results. Calculation of a myotube fusion index (\% nuclei incorporated into myotubes/total nuclei observed) yielded significant decreases in the $3 \mathrm{uM}, 5 \mathrm{uM}$, and SKO groups. The observed reduction in the myotube fusion index of these Sirt2 deficient cells was accompanied by differences in the phenotypes of the various groups. Myotube morphology was visibly impaired by different concentrations of BML266 (Fig. 8) at the 96h time point. The formation of myotubes was significantly reduced as higher levels of BML-266 were used. This coincided with a reduction in multinucleated myotubes and the total numbers of nuclei present within the samples.

In the SKO samples, the morphology of the $\mathrm{C} 2 \mathrm{C} 12$ cells was largely normal with healthy myoblasts being observed at later time points in which myotubes are usually present. The CRISPR/CAS9 transfected cells are shown (Fig. 9). These pictures show both the control

\section{Myotube Morphology}

$72 \mathrm{hrs}$

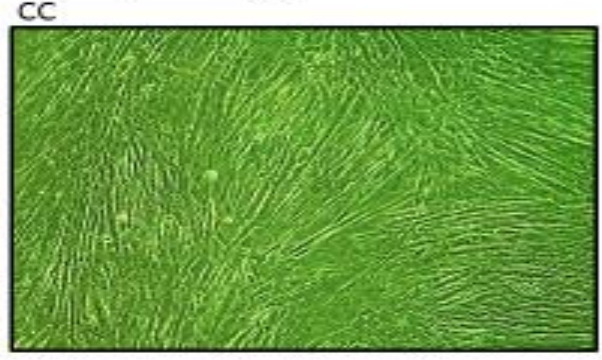

96hrs

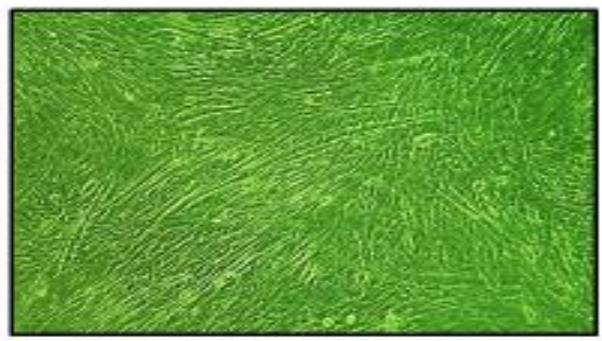

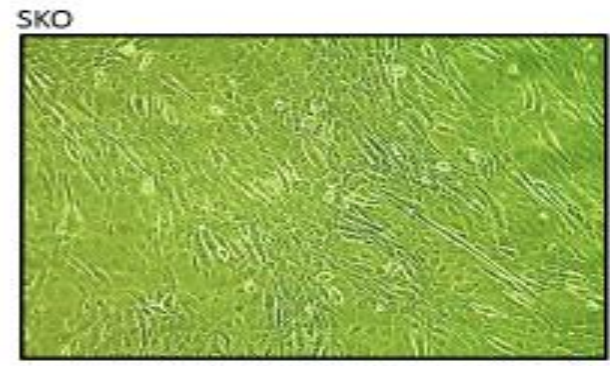

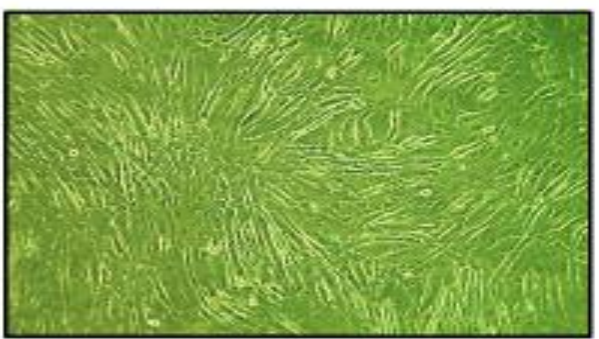

Figure 9: Representative Images of CRISPR/CAS9 transfected C2C12 cells with both the control plasmid (CC) and the knockout plasmid (SKO at the $72 \mathrm{~h} 96 \mathrm{hr}$ time points. CC cells appear to be developing myotubes at a faster rate than cells of the SKO line. 
CRISPR (CC) and Sirt2 knockout (SKO) cells at the 96-hour time point after serum starvation induced differentiation. SKO cells appear to have a higher percentage of myoblasts than the CC cells at the $96 \mathrm{hr}$ time point after the induction of differentiation. This is supported by the calculation of the myotube fusion index in figure 7.

\section{Specific Aim 2: Investigate the molecular signaling networks through which Sirt2 promotes} myoblast differentiation.

The working hypothesis is that Sirt2 promotes the differentiation of myoblasts by directly targeting and deacetylating cell cycle regulators such as pRB or E2F1. As a result of these interactions, proliferating myoblasts exit the cell cycle and enter into the differentiation program.

To identify the potential downstream protein interactions of Sirt2 immunoprecipitation experiments were performed. The results of one of these experiments are shown in figure 10.

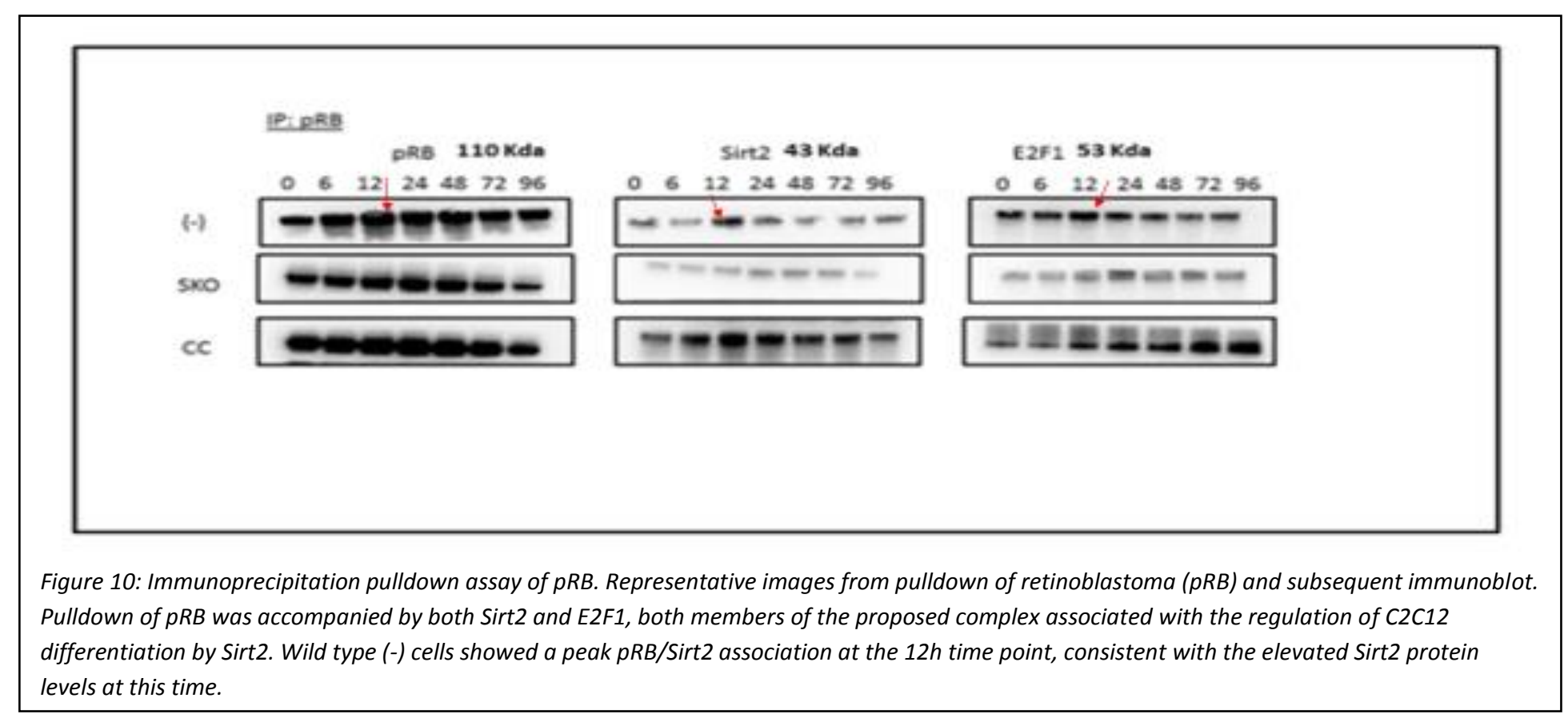

Pulldown of the retinoblastoma protein $\mathrm{pRB}$ revealed the presence of both Sirt2 and the proliferation inducing transcription factor E2F1. Sirt2 association with pRB was shown to peak at $12 \mathrm{~h}$ in the wild type cells, corresponding to the transient increase in Sirt2 protein expression 
previously observed. This association supports the proposed complex between $\mathrm{pRB}$ and Sirt2, with their association leading to the deacetylation of E2F1 thereby silencing the transcriptional signaling of myoblast proliferation and providing the stimulus for the onset of differentiation.

Pulldown of acetylated lysine was also performed and the acetylation status of E2F1 was measured to evaluate the function of the protein association observed in Fig. 10. Figure 11 shows

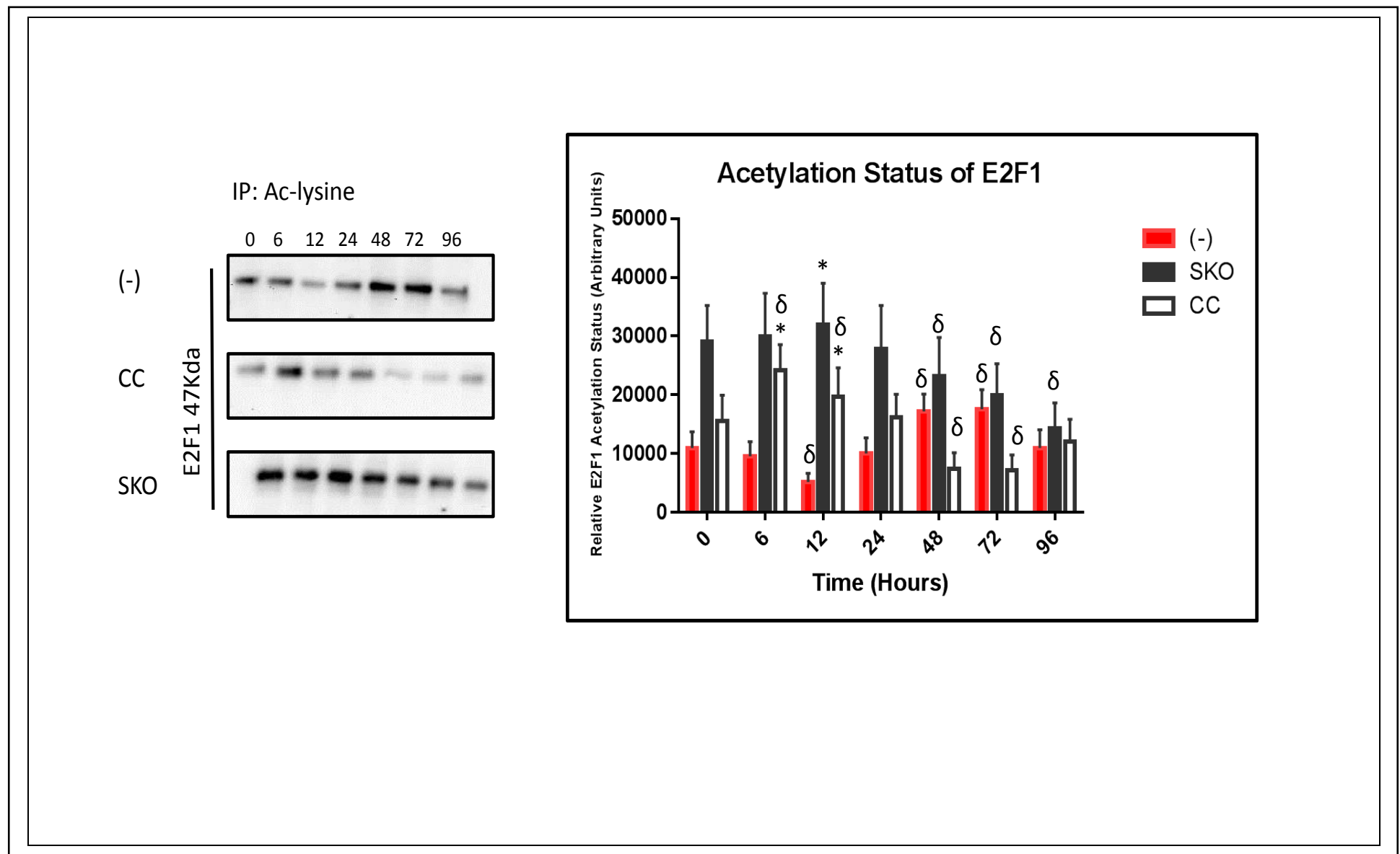

Figure 11: Acetylation status of E2F1 following pulldown of Ac-Lysine. * represents a significant difference from corresponding (-) time point with $p<0.05$. The $\delta$ represents a significant difference from 0 of the corresponding cell line. Data are presented as means \pm SEM with $n=3$.

the observed immunoprecipitation results. The acetylation status of E2F1 was significantly decreased at the $12 \mathrm{~h}$ time point in the wild type (-) cells. The Sirt 2 knockdown cell line exhibited a significantly increased E2F1 acetylation status indicating that the decreased level of Sirt2 present in these cells accounted for this increase. 
In addition to the proteins involved in the proposed complex (pRB, Sirt2, E2F1) p21 was also observed in the pull down of pRB (Fig. 12). Expression of $\mathrm{p} 21$ follows the same general trend seen in various other assays with an expression of $\mathrm{p} 21$ experiencing a transient increase at the $12 \mathrm{~h}$ time point. This expression was coupled with a decrease in p21 expression in the SKO cell line at the $12 \mathrm{~h}$ and $48 \mathrm{~h}$ time

$$
\text { IP: pRB }
$$
$\begin{array}{lllllll}0 & 6 & 12 & 24 & 48 & 72 & 96\end{array}$

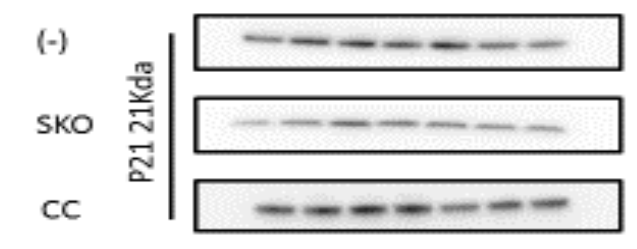

Figure 12: Protein levels of p21 in the principle cells lines following pulldown of $p R B$. Expression of $p 21$ is decreased at the $12 \mathrm{~h}$ and $48 \mathrm{~h}$ time points in comparison to the (-) cell line. The observed expression of $p 21$ is in accordance with the proposed $p R B$ differentiation inducing complex as p21 promotes the activity of $p R B$ by inhibiting the phosphorylation of $p R B$. This phosphorylated $p R B$ would thus be inactivated and unable to exert influence on downstream targets such as E2F1.

points following the general trends of Sirt2 regulation. This regulation of p21 supports the proposed $\mathrm{pRB} / \mathrm{Sirt} 2$ differentiation complex, as $\mathrm{p} 21$ is a positive regulator of $\mathrm{pRB}$ activity. 


\section{Chapter 5 - Discussion and Conclusions}

By the observations made throughout this experimentation, we propose that the $\mathrm{NAD}^{+}$ dependent sirtuin protein, Sirt2, transiently migrates to the nucleus during the early stage of C2C12 myoblast differentiation and promotes the differentiation process of these cells to become myotubes. We have observed a transient increase in the levels of Sirt2 protein during the early stages of $\mathrm{C} 2 \mathrm{C} 12$ myogenesis, followed by the induction of differentiation upon serum starvation. The increased levels of Sirt 2 are present when the C2C12 cells cease proliferation and exit from the cell cycle. This exit subsequently promotes the differentiation and fusion of myoblasts into myotubes. It appears that Sirt2 participates in the regulation of this mechanism through an association with the retinoblastoma protein, which leads to the eventual deacetylation and silencing of the proliferation inducing transcription factor E2F1.

The sirtuin family of proteins are known deacetylases and are involved in the regulation of a myriad of processes. Regarding muscular biology, the sirtuin family members, Sirt1 and Sirt3 have previously characterized roles that help regulate myogenesis, and the successful development and maintenance of healthy muscle fibers. For example, Sirt1 has been implicated as a positive regulator of myoblast proliferation. Sirt1 is recruited to muscle regulatory regions on chromatin and interacts with a MyoD/PCAF transcriptional complex and an MEF2 complex further downstream. Sirt1 can deacetylate and silence these transcription factors, thereby inhibiting C2C12 myoblast differentiation [67]. This inhibition of differentiation thus allows the myoblasts to remain in the growth and proliferative stage enabling the formation of a large pool of myoblasts which can later be used for myotube formation and the replenishment of the activated satellite cell pool. Sirt1 is also known to promote the proliferation of $\mathrm{C} 2 \mathrm{C} 12$ myoblasts through the inhibition 
of cell cycle inhibitors, such as p21 Waf/Cip1 and p27 Kip1 [68]. The mitochondrial sirtuin, Sirt3, is also involved in the regulation of myogenesis through positive regulation of myogenic differentiation [11], as Sirt3 deficient C2C12 myoblasts exhibited a marked decrease in the myoblast fusion index and a significant reduction of myogenic regulatory factor expression.

The close associations between these sirtuins $(1,3)$, and myogenesis prompted our interest in the cytosolic Sirt2, as Sirt2 shares classification with 1 and 3 as class 1 sirtuins. Therefore, exploring the regulation of Sirt2 during myogenesis was of particular interest. Initially, we sought to investigate the regulation of Sirt2 during the process of differentiating $\mathrm{C} 2 \mathrm{C} 12$ myoblasts in vitro. This led to the observation that Sirt2 protein expression is transiently increased during the early stages of myoblast differentiation, particularly at the $12 \mathrm{~h}$ time point. The protein expression of myogenic regulatory factors MyoD and Myogenin was also performed and exhibited significant increases of MyoD in the early stages of differentiation, followed by the induction of myogenin. The induction of myogenin corresponds to differentiation and the formation of myotubes. This observation prompted the utilization of several different cell lines to further elucidate this regulation, including a wild type line, a line supplemented with a pharmacological inhibitor of Sirt2, BML-266, and a Sirt2 knockdown (SKO) cell line generated through the use of a CRISPR/Cas9 plasmid. The following experimentation yielded several interesting results and helped to form the Sirt2 regulatory picture.

Immunocytochemistry was performed to examine the phenotype and nuclear count of the $\mathrm{C} 2 \mathrm{C} 12$ cells in each cell line. The results of this myotube fusion index in cell groups with inhibited Sirt2 function (BML-266 3uM, 5uM), or protein expression (SKO) showed inhibited myotube formation at the $96 \mathrm{~h}$ time point after the induction of differentiation. This impaired differentiation resulted in a noticeable decrease in the number of healthy myotubes present in these groups 
indicating that Sirt2 expression and activity plays a key role in the formation of myotubes and ultimately healthy myofibers. It is interesting that there was such a pronounced inhibition of myoblast fusion in the SKO group, as the total knockdown of Sirt2 expression compared to wild type was only approximately 50\%. This could be indicative of the necessity for Sirt2 in this differentiation process, and that other sirtuins, such as Sirt1 or Sirt3 did not take on a compensatory function in the absence of normal Sirt2 levels, or that they regulate differential functions during myogenesis. Indeed, the levels of Sirt1 and Sirt3 protein expression did not appear to fluctuate in the SKO group during the time course we examined and if they did change it did not rescue the myotube phenotype during this time point. Extending the time course may elicit these compensatory reactions and rescue a normal phenotype, especially form Sirt3 with its previously characterized regulation of differentiation, but we have not investigated that possibility at this time.

In addition to examining the expression and regulation of Sirt2 during our time course, possible downstream targets and effectors of Sirt2 were examined to elucidate the mechanisms by which Sirt2 promotes differentiation. Likely targets were identified as members related to the cell cycle, and exit from the cell cycle in particular. Previous studies have shown that Sirt2 can transiently migrate to the nucleus during the G2/M phase of the cell cycle and associate with chromatin structures $[25,75]$. This observation put Sirt2 in the nucleus during the cell cycle growth phase and prompted the hypothesis that Sirt2 can associate with transcription factors involved in cell cycle exit and subsequent differentiation. The retinoblastoma protein $\mathrm{pRB}$ was identified as a possible Sirt2 effector for its role as a regulator of differentiation in various cell types. For example, $\mathrm{pRB}$ is necessary for the completion of the muscle differentiation program and myogenic helix-loop-helix dependent transcription through a transcriptional link with MyoD [101]. Immunoprecipitation experimentation was performed on wild type, and CRISPR/Cas9 modified 
cell lines to identify protein Sirt2 protein interactions that could contribute to the positive regulation of differentiation Sirt2 displays. The results of these assays showed the interaction between Sirt2 and pRB which appeared to peak at the $12 \mathrm{~h}$ time point corresponding to the protein upregulation of Sirt2. In addition to pRB, p21 and the transcription factor E2F1 were also present in the immunoprecipitation assay. The associations displayed here led to the proposed model shown in Fig. 2. The hypothesis formed by this model involves the partnership of Sirt2 and pRB through the $\mathrm{pRB}$ binding domain. This complex is supported by previous observations of $\mathrm{pRB}$ forming a complex with HDACs and thereby leading to the deacetylation of E2F1 by HDAC resulting in the cessation of proliferation and the beginning of terminal differentiation. The results of the IP experimentation support the formation of such a complex during the time course of myogenesis, and the acetylation status of E2F1 is significantly increased at the $12 \mathrm{~h}$ time point in the SKO cell line, indicating that this complex was not able to form in those cells. The presence of p21 further shows that this complex exists and is related to the cell cycle and that Sirt2 plays a key role in mediating the switch from proliferation to differentiation.

There are significant implications raised by the results of this experimentation, including the ability of muscle fibers to regenerate and repair in aging. It is known that levels of the sirtuin proteins decrease with age, and the activity of the sirtuin cofactor $\mathrm{NAD}^{+}$is also impaired. This could impact the ability of satellite cells to proliferate in the case of Sirt1, and impairment in the ability of aged muscle fibers to regrow and repair in the event of Sirt2 deficiency. This may be a major contributor to the condition of sarcopenia and strategies aimed at supplementing sirtuin levels and activity in aged conditions may prove vital to improving the quality of life and rehabilitation outcomes in old individuals. Future work should be aimed towards validating these Sirt2 mechanisms in animal models and examining both the structure and function of muscles in 
both knockout and overexpression models. For example, at this time it is necessary to translate the mechanisms discovered in the $\mathrm{C} 2 \mathrm{C} 12$ myoblasts to animal models to examine the efficacy of this model in vivo. Transgenic mice will be developed to further elucidate these Sirt2 mechanisms. Sirt $2^{-/-}$and Sirt $2^{\text {STOP }}$ (global over expresser) mice will be acquired from the Jackson Laboratory and subsequently crossed with several models in our laboratory to develop several different genotypes using the Cre/loxP system. We will generate tissue specific Sirt2 ${ }^{-/-}$mice for both Pax $7^{+}$, (satellite cell knockout) and MCK, (muscle specific knockout). The same strategy will be used to generate tissue specific overexpression of Sirt2 in both the SC and muscle. Upon generation of these genotypes various experiments and assays will be performed to assess a variety of factors including muscle morphology, performance/physiology, protein content, RNA analysis, and recovery from injury following cardio toxin injection into the muscle. We will also examine this regulation in both young and aged mice to help elucidate any changes that occur with Sirt2 regulation of the muscles in aging, as both sirtuin and $\mathrm{NAD}^{+}$levels decrease with age. These experiments will serve to examine the activity of Sirt2 in vivo and determine whether or not it regulates myogenesis and myoblast differentiation in a more translational system. This will serve to increase our understanding of the role Sirt2 plays in the process of myogenesis, and how that process is altered with aging or disease. 


\section{Bibliography}

1. Mauro A. SATELLITE CELL OF SKELETAL MUSCLE FIBERS. J Biophys Biochem Cytol. 1961;9: 493-495.

2. Buckingham M, Bajard L, Chang T, Daubas $P$, Hadchouel J, Meilhac $S$, et al. The formation of skeletal muscle: from somite to limb. J Anat. 2003;202: 59-68. doi:10.1046/j.1469-

7580.2003.00139.x

3. Alway SE, Gonyea WJ, Davis ME. Muscle fiber formation and fiber hypertrophy during the onset of stretch-overload. Am J Physiol. 1990;259: C92-102.

4. Webster C, Blau HM. Accelerated age-related decline in replicative life-span of Duchenne muscular dystrophy myoblasts: implications for cell and gene therapy. Somat Cell Mol Genet. 1990;16: 557565.

5. Mitchell PO, Pavlath GK. Skeletal muscle atrophy leads to loss and dysfunction of muscle precursor cells. Am J Physiol - Cell Physiol. 2004;287: C1753-C1762. doi:10.1152/ajpcell.00292.2004

6. Guttridge DC, Mayo MW, Madrid LV, Wang CY, Baldwin AS. NF-kappaB-induced loss of MyoD messenger RNA: possible role in muscle decay and cachexia. Science. 2000;289: 2363-2366.

7. Penna F, Costamagna D, Fanzani A, Bonelli G, Baccino FM, Costelli P. Muscle Wasting and Impaired Myogenesis in Tumor Bearing Mice Are Prevented by ERK Inhibition. PLoS ONE. 2010;5. doi:10.1371/journal.pone.0013604

8. Mohamed JS, Lopez MA, Cox GA, Boriek AM. Ankyrin repeat domain protein 2 and inhibitor of DNA binding 3 cooperatively inhibit myoblast differentiation by physical interaction. J Biol Chem.

2013;288: 24560-24568. doi:10.1074/jbc.M112.434423

9. Rauh D, Fischer F, Gertz M, Lakshminarasimhan M, Bergbrede T, Aladini F, et al. An acetylome peptide microarray reveals specificities and deacetylation substrates for all human sirtuin isoforms. Nat Commun. 2013;4: 2327. doi:10.1038/ncomms3327

10. Ryall JG, Dell'Orso S, Derfoul A, Juan A, Zare H, Feng X, et al. The NAD(+)-dependent SIRT1 deacetylase translates a metabolic switch into regulatory epigenetics in skeletal muscle stem cells. Cell Stem Cell. 2015;16: 171-183. doi:10.1016/j.stem.2014.12.004

11. Abdel Khalek W, Cortade F, Ollendorff V, Lapasset L, Tintignac L, Chabi B, et al. SIRT3, a mitochondrial $N A D^{+}$-dependent deacetylase, is involved in the regulation of myoblast differentiation. PloS One. 2014;9: e114388. doi:10.1371/journal.pone.0114388

12. Haigis MC, Sinclair DA. Mammalian sirtuins: biological insights and disease relevance. Annu Rev Pathol. 2010;5: 253-295. doi:10.1146/annurev.pathol.4.110807.092250

13. Sebastián C, Satterstrom FK, Haigis MC, Mostoslavsky R. From sirtuin biology to human diseases: an update. J Biol Chem. 2012;287: 42444-42452. doi:10.1074/jbc.R112.402768 
14. Banerjee KK, Ayyub C, Ali SZ, Mandot V, Prasad NG, Kolthur-Seetharam U. dSir2 in the adult fat body, but not in muscles, regulates life span in a diet-dependent manner. Cell Rep. 2012;2: 14851491. doi:10.1016/j.celrep.2012.11.013

15. Viswanathan M, Guarente L. Regulation of Caenorhabditis elegans lifespan by sir-2.1 transgenes. Nature. 2011;477: E1-E2. doi:10.1038/nature10440

16. Rogina B, Helfand SL. Sir2 mediates longevity in the fly through a pathway related to calorie restriction. Proc Natl Acad Sci U S A. 2004;101: 15998-16003. doi:10.1073/pnas.0404184101

17. Tissenbaum HA, Guarente L. Increased dosage of a sir-2 gene extends lifespan in Caenorhabditis elegans. Nature. 2001;410: 227-230. doi:10.1038/35065638

18. Hsu WW, Wu B, Liu WR. Sirtuins 1 and 2 Are Universal Histone Deacetylases. ACS Chem Biol. 2016;11: 792-799. doi:10.1021/acschembio.5b00886

19. Wu G, Song C, Lu H, Jia L, Yang G, Shi X'e, et al. Sirt2 induces C2C12 myoblasts proliferation by activation of the ERK1/2 pathway. Acta Biochim Biophys Sin. 2014;46: 342-345. doi:10.1093/abbs/gmt151

20. Ji S, Doucette JR, Nazarali AJ. Sirt2 is a novel in vivo downstream target of Nkx2.2 and enhances oligodendroglial cell differentiation. J Mol Cell Biol. 2011; mjr009. doi:10.1093/jmcb/mjr009

21. Jing E, Gesta S, Ronald Kahn C. Sirt2 Regulates Adipocyte Differentiation Involving FoxO1 Acetylation/Deacetylation. Cell Metab. 2007;6: 105-114. doi:10.1016/j.cmet.2007.07.003

22. Li Z, Huang J, Yuan H, Chen Z, Luo Q, Lu S. SIRT2 inhibits non-small cell lung cancer cell growth through impairing Skp2-mediated p27 degradation. Oncotarget. 2016;7: 18927-18939. doi:10.18632/oncotarget.7816

23. Lynn EG, McLeod CJ, Gordon JP, Bao J, Sack MN. SIRT2 is a negative regulator of anoxiareoxygenation tolerance via regulation of 14-3-3 zeta and BAD in H9c2 cells. FEBS Lett. 2008;582: 2857-2862. doi:10.1016/j.febslet.2008.07.016

24. Krishnan J, Danzer C, Simka T, Ukropec J, Walter KM, Kumpf S, et al. Dietary obesity-associated Hif1 $\alpha$ activation in adipocytes restricts fatty acid oxidation and energy expenditure via suppression of the Sirt2-NAD+ system. Genes Dev. 2012;26: 259-270. doi:10.1101/gad.180406.111

25. Inoue $\mathrm{T}$, Hiratsuka $\mathrm{M}$, Osaki M, Oshimura $\mathrm{M}$. The molecular biology of mammalian SIRT proteins: SIRT2 in cell cycle regulation. Cell Cycle Georget Tex. 2007;6: 1011-1018. doi:10.4161/cc.6.9.4219

26. Serrano L, Martínez-Redondo P, Marazuela-Duque A, Vazquez BN, Dooley SJ, Voigt P, et al. The tumor suppressor SirT2 regulates cell cycle progression and genome stability by modulating the mitotic deposition of H4K20 methylation. Genes Dev. 2013; doi:10.1101/gad.211342.112

27. Dryden SC, Nahhas FA, Nowak JE, Goustin A-S, Tainsky MA. Role for Human SIRT2 NAD-Dependent Deacetylase Activity in Control of Mitotic Exit in the Cell Cycle. Mol Cell Biol. 2003;23: 3173-3185. doi:10.1128/MCB.23.9.3173-3185.2003 
28. Dimova DK, Dyson NJ. The E2F transcriptional network: old acquaintances with new faces. Oncogene. 2005;24: 2810-2826. doi:10.1038/sj.onc.1208612

29. Weinberg RA. The retinoblastoma protein and cell cycle control. Cell. 1995;81: 323-330.

30. Mittnacht S. Control of pRB phosphorylation. Curr Opin Genet Dev. 1998;8: 21-27. doi:10.1016/S0959-437X(98)80057-9

31. Wong S, Weber JD. Deacetylation of the retinoblastoma tumour suppressor protein by SIRT1. Biochem J. 2007;407: 451-460. doi:10.1042/BJ20070151

32. Arora A, Dey CS. SIRT2 negatively regulates insulin resistance in $\mathrm{C} 2 \mathrm{C} 12$ skeletal muscle cells. Biochim Biophys Acta. 2014;1842: 1372-1378. doi:10.1016/j.bbadis.2014.04.027

33. Liu G, Park S-H, Imbesi M, Nathan WJ, Zou X, Zhu Y, et al. Loss of NAD-Dependent Protein Deacetylase Sirtuin-2 Alters Mitochondrial Protein Acetylation and Dysregulates Mitophagy. Antioxid Redox Signal. 2016; doi:10.1089/ars.2016.6662

34. Hamai N, Nakamura M, Asano A. Inhibition of mitochondrial protein synthesis impaired C2C12 myoblast differentiation. Cell Struct Funct. 1997;22: 421-431.

35. W K, Z P, K R. Chloramphenicol, an inhibitor of mitochondrial protein synthesis, inhibits myoblast fusion and myotube differentiation. Folia Histochem Cytobiol. 1992;31: 9-13.

36. Rochard P, Rodier A, Casas F, Cassar-Malek I, Marchal-Victorion S, Daury L, et al. Mitochondrial activity is involved in the regulation of myoblast differentiation through myogenin expression and activity of myogenic factors. J Biol Chem. 2000;275: 2733-2744.

37. Yudoh K, Karasawa R, Ishikawa J. Age-related Decrease of Sirtuin 2 Protein in Human Peripheral Blood Mononuclear Cells. Curr Aging Sci. 2015;8: 256-258.

38. Zeng L, Yang Y, Hu Y, Sun Y, Du Z, Xie Z, et al. Age-related decrease in the mitochondrial sirtuin deacetylase Sirt3 expression associated with ROS accumulation in the auditory cortex of the mimetic aging rat model. PloS One. 2014;9: e88019. doi:10.1371/journal.pone.0088019

39. Kumar R, Chaterjee P, Sharma PK, Singh AK, Gupta A, Gill K, et al. Sirtuin1: a promising serum protein marker for early detection of Alzheimer's disease. PloS One. 2013;8: e61560. doi:10.1371/journal.pone.0061560

40. Kumar R, Mohan N, Upadhyay AD, Singh AP, Sahu V, Dwivedi S, et al. Identification of serum sirtuins as novel noninvasive protein markers for frailty. Aging Cell. 2014;13: 975-980. doi:10.1111/acel.12260

41. Gomes AP, Price NL, Ling AJY, Moslehi JJ, Montgomery MK, Rajman L, et al. Declining NAD+ Induces a Pseudohypoxic State Disrupting Nuclear-Mitochondrial Communication during Aging. Cell. 2013;155: 1624-1638. doi:10.1016/j.cell.2013.11.037 
42. Jang YC, Sinha M, Cerletti M, Dall'Osso C, Wagers AJ. Skeletal Muscle Stem Cells: Effects of Aging and Metabolism on Muscle Regenerative Function. Cold Spring Harb Symp Quant Biol. 2011;76: 101-111. doi:10.1101/sqb.2011.76.010652

43. Yin H, Price F, Rudnicki MA. Satellite Cells and the Muscle Stem Cell Niche. Physiol Rev. 2013;93: 23-67. doi:10.1152/physrev.00043.2011

44. Kuang S, Kuroda K, Le Grand F, Rudnicki MA. Asymmetric Self-Renewal and Commitment of Satellite Stem Cells in Muscle. Cell. 2007;129: 999-1010. doi:10.1016/j.cell.2007.03.044

45. Wang YX, Rudnicki MA. Satellite cells, the engines of muscle repair. Nat Rev Mol Cell Biol. 2011;13: 127-133. doi:10.1038/nrm3265

46. Wagers AJ, Conboy IM. Cellular and Molecular Signatures of Muscle Regeneration: Current Concepts and Controversies in Adult Myogenesis. Cell. 2005;122: 659-667. doi:10.1016/j.cell.2005.08.021

47. Kuang S, Rudnicki MA. The emerging biology of satellite cells and their therapeutic potential. Trends Mol Med. 2008;14: 82-91. doi:10.1016/j.molmed.2007.12.004

48. Seale P, Sabourin LA, Girgis-Gabardo A, Mansouri A, Gruss P, Rudnicki MA. Pax7 is required for the specification of myogenic satellite cells. Cell. 2000;102: 777-786.

49. Bentzinger CF, von Maltzahn J, Rudnicki MA. Extrinsic regulation of satellite cell specification. Stem Cell Res Ther. 2010;1: 27. doi:10.1186/scrt27

50. Konieczny SF, Emerson CP. 5-Azacytidine induction of stable mesodermal stem cell lineages from 10T1/2 cells: evidence for regulatory genes controlling determination. Cell. 1984;38: 791-800.

51. Devlin RB, Emerson CP. Coordinate regulation of contractile protein synthesis during myoblast differentiation. Cell. 1978;13: 599-611.

52. Konigsberg IR. Clonal analysis of myogenesis. Science. 1963;140: 1273-1284.

53. Braun T, Bober E, Winter B, Rosenthal N, Arnold HH. Myf-6, a new member of the human gene family of myogenic determination factors: evidence for a gene cluster on chromosome 12. EMBO J. 1990;9: 821-831.

54. Rhodes SJ, Konieczny SF. Identification of MRF4: a new member of the muscle regulatory factor gene family. Genes Dev. 1989;3: 2050-2061.

55. Wright WE, Sassoon DA, Lin VK. Myogenin, a factor regulating myogenesis, has a domain homologous to MyoD. Cell. 1989;56: 607-617.

56. Edmondson DG, Olson EN. A gene with homology to the myc similarity region of MyoD1 is expressed during myogenesis and is sufficient to activate the muscle differentiation program. Genes Dev. 1989;3: 628-640. doi:10.1101/gad.3.5.628 
57. Braun T, Bober E, Buschhausen-Denker G, Kohtz S, Grzeschik KH, Arnold HH, et al. Differential expression of myogenic determination genes in muscle cells: possible autoactivation by the Myf gene products. EMBO J. 1989;8: 3617-3625.

58. Thayer MJ, Tapscott SJ, Davis RL, Wright WE, Lassar AB, Weintraub H. Positive autoregulation of the myogenic determination gene MyoD1. Cell. 1989;58: 241-248.

59. Punch VG, Jones AE, Rudnicki MA. Transcriptional networks that regulate muscle stem cell function. Wiley Interdiscip Rev Syst Biol Med. 2009;1: 128-140. doi:10.1002/wsbm.11

60. Montarras D, Morgan J, Collins C, Relaix F, Zaffran S, Cumano A, et al. Direct isolation of satellite cells for skeletal muscle regeneration. Science. 2005;309: 2064-2067.

doi:10.1126/science.1114758

61. Collins CA, Partridge TA. Self-renewal of the adult skeletal muscle satellite cell. Cell Cycle Georget Tex. 2005;4: 1338-1341. doi:10.4161/cc.4.10.2114

62. Brack AS, Conboy IM, Conboy MJ, Shen J, Rando TA. A temporal switch from notch to Wnt signaling in muscle stem cells is necessary for normal adult myogenesis. Cell Stem Cell. 2008;2: 50-59. doi:10.1016/j.stem.2007.10.006

63. Nabeshima Y, Hanaoka K, Hayasaka M, Esumi E, Li S, Nonaka I, et al. Myogenin gene disruption results in perinatal lethality because of severe muscle defect. Nature. 1993;364: 532-535. doi:10.1038/364532a0

64. Vachharajani VT, Liu T, Wang X, Hoth JJ, Yoza BK, McCall CE. Sirtuins Link Inflammation and Metabolism. J Immunol Res. 2016;2016: e8167273. doi:10.1155/2016/8167273

65. Horio Y, Hayashi T, Kuno A, Kunimoto R. Cellular and molecular effects of sirtuins in health and disease. Clin Sci Lond Engl 1979. 2011;121: 191-203. doi:10.1042/CS20100587

66. Hori YS, Kuno A, Hosoda R, Tanno M, Miura T, Shimamoto K, et al. Resveratrol ameliorates muscular pathology in the dystrophic mdx mouse, a model for Duchenne muscular dystrophy. J Pharmacol Exp Ther. 2011;338: 784-794. doi:10.1124/jpet.111.183210

67. Pardo PS, Boriek AM. The physiological roles of Sirt1 in skeletal muscle. Aging. 2011;3: 430-437.

68. Rathbone CR, Booth FW, Lees SJ. Sirt1 increases skeletal muscle precursor cell proliferation. Eur J Cell Biol. 2009;88: 35-44. doi:10.1016/j.ejcb.2008.08.003

69. Palacios OM, Carmona JJ, Michan S, Chen KY, Manabe Y, lii JLW, et al. Diet and exercise signals regulate SIRT3 and activate AMPK and PGC-1 $\alpha$ in skeletal muscle. Aging. 2009;1: 771-783. doi:10.18632/aging.100075

70. Joseph A-M, Adhihetty PJ, Buford TW, Wohlgemuth SE, Lees HA, Nguyen LM-D, et al. The impact of aging on mitochondrial function and biogenesis pathways in skeletal muscle of sedentary high- and low-functioning elderly individuals. Aging Cell. 2012;11: 801-809. doi:10.1111/j.14749726.2012.00844.x 
71. Lanza IR, Short DK, Short KR, Raghavakaimal S, Basu R, Joyner MJ, et al. Endurance Exercise as a Countermeasure for Aging. Diabetes. 2008;57: 2933-2942. doi:10.2337/db08-0349

72. Wang F, Nguyen $M$, Qin FX-F, Tong Q. SIRT2 deacetylates FOXO3a in response to oxidative stress and caloric restriction. Aging Cell. 2007;6: 505-514. doi:10.1111/j.1474-9726.2007.00304.x

73. Kim H-S, Vassilopoulos A, Wang R-H, Lahusen T, Xiao Z, Xu X, et al. SIRT2 maintains genome integrity and suppresses tumorigenesis through regulating APC/C activity. Cancer Cell. 2011;20: 487-499. doi:10.1016/j.ccr.2011.09.004

74. Maxwell MM, Tomkinson EM, Nobles J, Wizeman JW, Amore AM, Quinti L, et al. The Sirtuin 2 microtubule deacetylase is an abundant neuronal protein that accumulates in the aging CNS. Hum Mol Genet. 2011;20: 3986-3996. doi:10.1093/hmg/ddr326

75. Vaquero A, Scher MB, Lee DH, Sutton A, Cheng H-L, Alt FW, et al. SirT2 is a histone deacetylase with preference for histone H4 Lys 16 during mitosis. Genes Dev. 2006;20: 1256-1261. doi:10.1101/gad.1412706

76. Inoue T, Hiratsuka M, Osaki M, Yamada H, Kishimoto I, Yamaguchi S, et al. SIRT2, a tubulin deacetylase, acts to block the entry to chromosome condensation in response to mitotic stress. Oncogene. 2007;26: 945-957. doi:10.1038/sj.onc.1209857

77. North BJ, Marshall BL, Borra MT, Denu JM, Verdin E. The human Sir2 ortholog, SIRT2, is an NAD+dependent tubulin deacetylase. Mol Cell. 2003;11: 437-444.

78. Nogales E. Structural insights into microtubule function. Annu Rev Biochem. 2000;69: 277-302. doi:10.1146/annurev.biochem.69.1.277

79. MacRae TH. Tubulin post-translational modifications--enzymes and their mechanisms of action. Eur J Biochem. 1997;244: 265-278.

80. Li W, Zhang B, Tang J, Cao Q, Wu Y, Wu C, et al. Sirtuin 2, a mammalian homolog of yeast silent information regulator-2 longevity regulator, is an oligodendroglial protein that decelerates cell differentiation through deacetylating alpha-tubulin. J Neurosci Off J Soc Neurosci. 2007;27: 26062616. doi:10.1523/JNEUROSCI.4181-06.2007

81. Wang F, Tong Q. SIRT2 suppresses adipocyte differentiation by deacetylating FOXO1 and enhancing FOXO1's repressive interaction with PPARgamma. Mol Biol Cell. 2009;20: 801-808. doi:10.1091/mbc.E08-06-0647

82. Zhu H, Zhao L, Wang E, Dimova N, Liu G, Feng Y, et al. The QKI-PLP pathway controls SIRT2 abundance in CNS myelin. Glia. 2012;60: 69-82. doi:10.1002/glia.21248

83. Calnan DR, Brunet A. The FoxO code. Oncogene. 2008;27: 2276-2288. doi:10.1038/onc.2008.21

84. Zhang H, Park S-H, Pantazides BG, Karpiuk O, Warren MD, Hardy CW, et al. SIRT2 directs the replication stress response through CDK9 deacetylation. Proc Natl Acad Sci U S A. 2013;110: 13546-13551. doi:10.1073/pnas.1301463110 
85. North BJ, Rosenberg MA, Jeganathan KB, Hafner AV, Michan S, Dai J, et al. SIRT2 induces the checkpoint kinase BubR1 to increase lifespan. EMBO J. 2014;33: 1438-1453.

doi:10.15252/embj.201386907

86. Giacinti C, Giordano A. RB and cell cycle progression. Oncogene. 2006;25: 5220-5227. doi:10.1038/sj.onc.1209615

87. Attwooll C, Denchi EL, Helin K. The E2F family: specific functions and overlapping interests. EMBO J. 2004;23: 4709-4716. doi:10.1038/sj.emboj.7600481

88. Nevins JR. E2F: a link between the Rb tumor suppressor protein and viral oncoproteins. Science. 1992;258: 424-429.

89. Chan HM, Krstic-Demonacos M, Smith L, Demonacos C, La Thangue NB. Acetylation control of the retinoblastoma tumour-suppressor protein. Nat Cell Biol. 2001;3: 667-674. doi:10.1038/35083062

90. Nguyen DX, Baglia LA, Huang S-M, Baker CM, McCance DJ. Acetylation regulates the differentiation-specific functions of the retinoblastoma protein. EMBO J. 2004;23: 1609-1618. doi:10.1038/sj.emboj.7600176

91. Macaluso M, Montanari M, Cinti C, Giordano A. Modulation of cell cycle components by epigenetic and genetic events. Semin Oncol. 2005;32: 452-457. doi:10.1053/j.seminoncol.2005.07.009

92. Harbour JW, Dean DC. The Rb/E2F pathway: expanding roles and emerging paradigms. Genes Dev. 2000;14: 2393-2409. doi:10.1101/gad.813200

93. Takaki T, Fukasawa K, Suzuki-Takahashi I, Hirai H. Cdk-mediated phosphorylation of pRB regulates HDAC binding in vitro. Biochem Biophys Res Commun. 2004;316: 252-255.

doi:10.1016/j.bbrc.2004.02.044

94. Brehm A, Miska EA, McCance DJ, Reid JL, Bannister AJ, Kouzarides T. Retinoblastoma protein recruits histone deacetylase to repress transcription. Nature. 1998;391: 597-601.

doi:10.1038/35404

95. Kingston RE, Narlikar GJ. ATP-dependent remodeling and acetylation as regulators of chromatin fluidity. Genes Dev. 1999;13: 2339-2352.

96. Luo RX, Postigo AA, Dean DC. Rb Interacts with Histone Deacetylase to Repress Transcription. Cell. 1998;92: 463-473. doi:10.1016/S0092-8674(00)80940-X

97. Kaelin WG. Functions of the retinoblastoma protein. BioEssays. 1999;21: 950-958. doi:10.1002/(SICI)1521-1878(199911)21:11<950::AID-BIES7>3.0.CO;2-D

98. Trouche D, Cook A, Kouzarides T. The CBP Co-Activator Stimulates E2F1/DP1 Activity. Nucleic Acids Res. 1996;24: 4139-4145. doi:10.1093/nar/24.21.4139

99. Martínez-Balbás MA, Bauer U-M, Nielsen SJ, Brehm A, Kouzarides T. Regulation of E2F1 activity by acetylation. EMBO J. 2000;19: 662-671. doi:10.1093/emboj/19.4.662 
100. Dyson N. The regulation of E2F by pRB-family proteins. Genes Dev. 1998;12: 2245-2262.

101. De Falco G, Comes F, Simone C. pRb: master of differentiation. Coupling irreversible cell cycle withdrawal with induction of muscle-specific transcription. Oncogene. 2006;25: 5244-5249. doi:10.1038/sj.onc.1209623

102. Guo K, Walsh K. Inhibition of myogenesis by multiple cyclin-Cdk complexes. Coordinate regulation of myogenesis and cell cycle activity at the level of E2F. J Biol Chem. 1997;272: 791-797.

103. Novitch BG, Spicer DB, Kim PS, Cheung WL, Lassar AB. pRb is required for MEF2-dependent gene expression as well as cell-cycle arrest during skeletal muscle differentiation. Curr Biol CB. 1999;9: 449-459.

104. Nh H, E M, M A, HI D, Mj VG, M V den B, et al. Mitochondria in cultured human muscle cells depleted of mitochondrial DNA. Eur J Cell Biol. 1993;61: 400-408.

105. Seyer P, Grandemange S, Busson M, Carazo A, Gamaléri F, Pessemesse L, et al. Mitochondrial activity regulates myoblast differentiation by control of c-Myc expression. J Cell Physiol. 2006;207: 75-86. doi:10.1002/jcp.20539

106. Moyes CD, Mathieu-Costello OA, Tsuchiya N, Filburn C, Hansford RG. Mitochondrial biogenesis during cellular differentiation. Am J Physiol. 1997;272: C1345-1351.

107. Remels AHV, Langen RCJ, Schrauwen P, Schaart G, Schols AMWJ, Gosker HR. Regulation of mitochondrial biogenesis during myogenesis. Mol Cell Endocrinol. 2010;315: 113-120. doi:10.1016/j.mce.2009.09.029 


\section{Appendix}

A.) Plasmid design used for Sirt2 KO experiments (Santa Cruz Biotechnology).
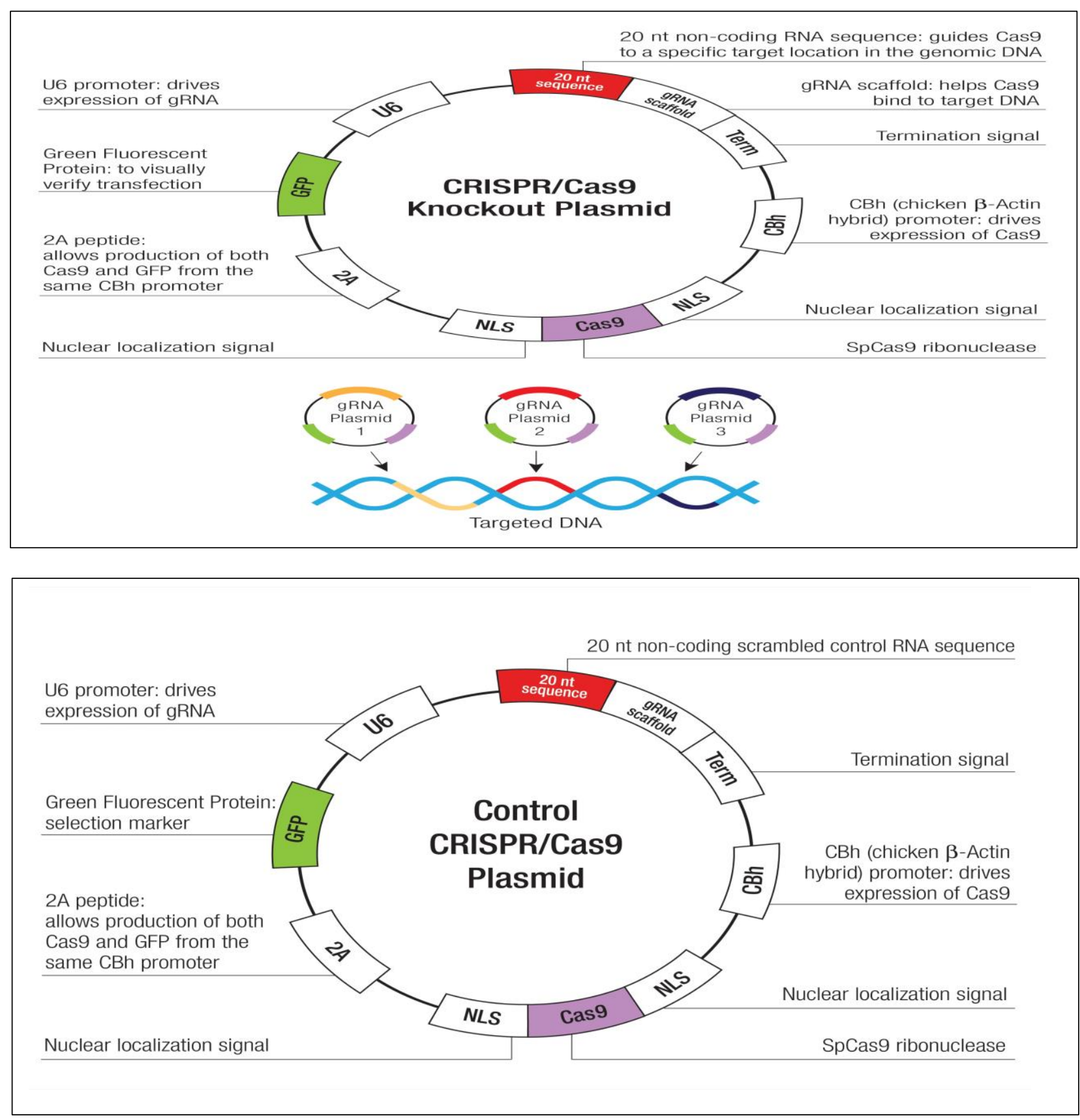